\title{
PMP22 Regulates Cholesterol Trafficking and ABCA1-Mediated Cholesterol Efflux
}

\author{
다e Zhou, ${ }^{1}$ - Joshua R. Miles, ${ }^{3,4}$ ๑Hagai Tavori, ${ }^{3,4}$ Min Lin, ${ }^{1}$-Habibeh Khoshbouei, ${ }^{1}$ @David R. Borchelt, ${ }^{1}$ \\ Hannah Bazick, ${ }^{1}$ Gary E. Landreth, ${ }^{5}$ Sooyeon Lee, ${ }^{1}{ }^{\circledR}$ Sergio Fazio, ${ }^{3,4}$ and ${ }^{\oplus}$ Lucia Notterpek ${ }^{1,2}$ \\ ${ }^{1}$ Department of Neuroscience, ${ }^{2}$ Department of Neurology, College of Medicine, McKnight Brain Institute, University of Florida, Gainesville, Florida 32610 , \\ ${ }^{3}$ Department of Medicine, ${ }^{4}$ Department of Physiology and Pharmacology, Knight Cardiovascular Institute, Center of Preventive Cardiology, Oregon Health \\ \& Science University, Portland, Oregon 27332, and ${ }^{5}$ Department of Neurosciences, Indiana University, Indianapolis, Indiana 46202
}

The absence of functional peripheral myelin protein 22 (PMP22) is associated with shortened lifespan in rodents and severe peripheral nerve myelin abnormalities in several species including humans. Schwann cells and nerves from PMP22 knock-out (K0) mice show deranged cholesterol distribution and aberrant lipid raft morphology, supporting an unrecognized role for PMP22 in cellular lipid metabolism. To examine the mechanisms underlying these abnormalities, we studied Schwann cells and nerves from male and female PMP22 K0 mice. Whole-cell current-clamp recordings in cultured Schwann cells revealed increased membrane capacitance and decreased membrane resistance in the absence of PMP22, which was consistent with a reduction in membrane cholesterol. Nerves from PMP22-deficient mice contained abnormal lipid droplets, with both mRNA and protein levels of apolipoprotein E (apoE) and ATPbinding cassette transporter A1 (ABCA1) being highly upregulated. Despite the upregulation of ABCA1 and apoE, the absence of PMP22 resulted in reduced localization of the transporter to the cell membrane and diminished secretion of apoE. The absence of PMP22 also impaired ABCA1-mediated cholesterol efflux capacity. In nerves from ABCA1 KO mice, the expression of PMP22 was significantly elevated and the subcellular processing of the overproduced protein was aberrant. In wild-type samples, double immunolabeling identified overlapping distribution of PMP22 and ABCA1 at the Schwann cell plasma membrane and the two proteins were coimmunoprecipitated from Schwann cell and nerve lysates. Together, these results reveal a novel role for PMP22 in regulating lipid metabolism and cholesterol trafficking through functional interaction with the cholesterol efflux regulatory protein ABCA1.

Key words: apoE; ATP-binding cassette transporter 1; cholesterol efflux; hereditary neuropathy; peripheral myelin protein 22; Schwann cell

Significance Statement

Understanding the subcellular events that underlie abnormal myelin formation in hereditary neuropathies is critical for advancing therapy development. Peripheral myelin protein 22 (PMP22) is an essential peripheral myelin protein because its genetic abnormalities account for $\sim 80 \%$ of hereditary neuropathies. Here, we demonstrate that in the absence of PMP22, the cellular and electrophysiological properties of the Schwann cells' plasma membrane are altered and cholesterol trafficking and lipid homeostasis are perturbed. The molecular mechanisms for these abnormalities involve a functional interplay among PMP22, cholesterol, apolipoprotein E, and the major cholesterol-efflux transporter protein ATP-binding cassette transporter A1 (ABCA1). These findings establish a critical role for PMP22 in the maintenance of cholesterol homeostasis in Schwann cells.

\section{Introduction}

Cholesterol, one of the main lipids in myelin, is essential for glial membrane expansion, as severe myelin defects in both the CNS

Received Nov. 14, 2018; revised April 22, 2019; accepted April 26, 2019.

Author contributions: Y.Z., H.T., H.K., D.R.B., S.F., and L.N. designed research; Y.Z., J.R.M., M.L., and H.B. performed research; Y.Z., J.R.M., H.T., M.L., H.K., and S.F. analyzed data; Y.Z. wrote the first draft of the paper; Y.Z., H.T., H.K., D.R.B., H.B., G.E.L., S.L., S.F., and L.N. edited the paper; G.E.L. contributed unpublished reagents/analytic tools; L.N. wrote the paper.

This work was supported by the Facial Pain Research Foundation and the University of Florida College of Medicine (L.N.). Studies at Oregon Health \& Sciences University were partially supported by the National Institutes of Health (Grant HL57986 to S.F.) We thank Angela Corona for collection of the ABCA1-deficient mouse nerves, Joseph J. and PNS occur after genetic ablation of squalene synthase, an enzyme in the cholesterol synthetic pathway (Saher et al., 2005, 2009). Cellular lipid content is controlled by the sterol-regulatory
Lebowitz for advice in fluorescent image quantification, and the NIH Shared Instrumentation Grant program (Grant 1S100D020026) for the scanning confocal images.

We dedicate this article to the memory of Professor Eric M. Shooter, who was instrumental in the establishment of this mouse model of PMP22 deficiency.

The authors declare no competing financial interests.

Correspondence should be addressed to Lucia Notterpek at Notterpek@ufl.edu.

https://doi.org/10.1523/JNEUROSCI.2942-18.2019

Copyright $\odot 2019$ the authors 
element (SRE) binding proteins (SREBP) 2 and 1c (Shimano et al., 1996) and by the liver X-receptor (LXR) (Keller et al., 1993; Venkateswaran et al., 2000) pathways. The SRE is a sensing system that monitors membrane cholesterol deficiency and regulates de novo lipogenesis of cholesterol (through SREBP-2), and triglycerides and phospholipids (through SREBP-1c) (Horton et al., 2002). Conversely, the LXR system senses cholesterol excesses and modulates the cholesterol efflux machinery through LXR/ LXR or LXR/RXR dimerization and activation, including the expression of ATP-binding cassette transporter 1 (ABCA1) and the acceptor protein apolipoprotein $\mathrm{E}$ (apoE) (Joseph and Tontonoz, 2003). In Tangier disease, due to loss-of-function mutations in the gene for ABCA1, and as characterized by intracellular lipid accumulation in Schwann cells, $\sim 50 \%$ of the patients develop peripheral neuropathy (Hobbs and Rader, 1999; Zyss et al., 2012).

Peripheral neuropathies comprise a heterogeneous group of disorders with $>100$ distinct types. Approximately $80 \%$ of hereditary neuropathies are linked with abnormal expression of the peripheral myelin protein 22 (PMP22) gene (Ekins et al., 2015), which causes disease by three distinct mechanisms, including overexpression (gene duplication), gene deletion or truncation (haploinsufficiency), and point mutations (Li et al., 2013; van Paassen et al., 2014). Heterozygous deletion of the PMP22 gene is responsible for hereditary neuropathy with liability to pressure palsies (HNPP), an autosomal-dominant, compression-induced neuropathy (Chance et al., 1994). Homozygous HNPP, a rare condition, presents as an early-onset severe neuropathy with pronounced motor and sensory deficits (Saporta et al., 2011). Various rodent models confirm the requirement for PMP22 in peripheral nerve myelination and provide insights on the role of the protein in glial biology.

In the PNS, Schwann cells synthesize PMP22, the culprit protein in the majority of hereditary neuropathies. PMP22 is a hydrophobic integral membrane glycoprotein with demonstrated roles in cell differentiation and membrane expansion (Suter and Snipes, 1995). Whereas PMP22 is broadly expressed in the body, affected individuals and animals with PMP22 mutations develop demyelinating or dysmyelinating peripheral neuropathy with varying severities. In the adult mature nerve, PMP22 is localized to the compact portion of myelin, where it potentially serves a structural role (Suter and Snipes, 1995). Binding partners of PMP22 include the major protein constituent of PNS myelin, protein zero (P0), and the $\alpha 6 \beta 4$ integrin complex (D'Urso et al., 1999; Amici et al., 2006). Based on the identification of a highly conserved cholesterol recognition CRAC motif in the fourth transmembrane domain of PMP22 (Gould et al., 2005; Sedzik et al., 2013) and a conserved palmitoylation site at C85 (Zoltewicz et al., 2012), a potential interaction with lipids is also likely.

How altered expression of PMP22 causes the distinct forms of hereditary neuropathies and how the pathologies relate to the biological function of the protein in Schwann cells remains a puzzle. Given the vital role of lipids in myelin biology, the recognized lipid abnormalities in PMP22-mutant neuropathic Trembler mice and the potential connection between cholesterol and PMP22 (Heape et al., 1986; Juguelin et al., 1986; Lee et al., 2014), we investigated whether PMP22 directly affects lipid metabolism. For our studies, we used systemic PMP22 knock-out (KO) mice, which develop early-onset severe neuropathy with altered cholesterol distribution and elevated apoE production in affected peripheral nerves (Amici et al., 2006; Lee et al., 2014). Here, we demonstrate that PMP22 is critical for cholesterol trafficking and ABCA1-dependent cholesterol efflux in Schwan cells, implicating aberrant cholesterol metabolism in the pathogenesis of dysmyelinating and demyelinating neuropathies.

\section{Materials and Methods}

Ethics statement. All experiments with animals were performed after approval by the University of Florida Animal Care and Use Committee. Breeding colonies of PMP22 KO mice (Amici et al., 2006) were housed at the University of Florida under specific-pathogen-free conditions. WT and PMP22 KO littermates generated from heterozygous breeders on 129 S1/SvImJ background were used for tissue collection and cell culture. Genotyping was performed on genomic DNA isolated from tail biopsies and determined by PCR (Amici et al., 2006). Before each tissue collection, animals were fasted for $16 \mathrm{~h}$ and weighed. After euthanasia, blood was cleared by transcardial perfusion with cold PBS. ABCA1 KO $\left(\right.$ Abcal ${ }^{\mathrm{tm} 1 \mathrm{Jdm}}$ ) mice (Aiello et al., 2003) were purchased from The Jackson Laboratory.

Cell culture studies. Mouse Schwann cells were isolated from sciatic nerves of genotyped postnatal day 5 (P5) to P8 littermates as described previously (Fortun et al., 2006) with modifications. In brief, dissected nerves were maintained in DMEM supplemented with Ham's F12 (Thermo Fisher Scientific), 10\% FBS, and gentamicin (20 $\mu \mathrm{g} / \mathrm{ml}$; Invitrogen) for 2-4 d. Nerves were then digested with $0.03 \%$ collagenase, 1.25 units $/ \mathrm{ml}$ dispase, and $0.01 \%$ hyaluronidase type 1 (Worthington). After trituration, the cell suspension was preplated for $30 \mathrm{~min}$ to allow the adhesion of fibroblasts and unattached cells were moved onto poly-Llysine-coated dishes. After treatment with $5 \mu \mathrm{M}$ cytosine arabinoside (Sigma-Aldrich) for 2-4 d, Schwann cells were maintained in DMEMF12 with 10\% FBS, $20 \mu \mathrm{g} / \mathrm{ml}$ bovine pituitary extract (Biomedical Technologies), and $5 \mu \mathrm{M}$ forskolin (Calbiochem). Mouse nerve fibroblasts (MNFs) represented the cells that adhered to the tissue culture plate during the first $30 \mathrm{~min}$ after plating. MNFs were expanded in DMEM medium supplemented with gentamicin and 10\% FCS (Hyclone). Rat Schwann cells were cultured from the sciatic nerves of neonatal pups, as described previously (Notterpek et al., 1999).

shRNA and WT-PMP22 plasmid transfection. Before transfection, rat Schwann cells were plated on poly-L-lysine-coated plates and maintained until reaching $70 \%$ confluence. Transient transfections with WTPMP22-Myc plasmids (Johnson et al., 2005) and scrambled or pooled rat PMP22 shRNA plasmids containing GFP reporters (Applied Biological Materials) were performed using lipofectamine 3000 (Invitrogen) in Opti-MEM medium (Thermo Fisher Scientific) (Rao et al., 2015). The sequences (from $5^{\prime}-3^{\prime}$ ) of PMP22 shRNA are as follows: 40 GCGGT GCTAGTGTTGCTCTTCGTCTCCAC; 161 ACTCCTCATCTGTGAG CGAATGGCTTCAG; 313 CTTGCTGGTCTGTGTGTGATGAGTGC AGC; and 438 CCTCCTTAGTGGCATCATCTACGTGATCC.

Twenty-four hours later, cells with WT-PMP22 transfection were lysed for coimmunoprecipitation (co-IP). Cells transfected with scrambled or PMP22 shRNA were directly processed for cholesterol efflux assay or switched to DMEM with $10 \%$ lipoprotein-deficient serum (LPDS) medium for another $48 \mathrm{~h}$ before immunostaining.

Whole-cell current-clamp recording. The membrane properties of WT and PM22 KO Schwann cells were determined via whole-cell currentclamp recording. The WT or PM22 KO Schwann cells were continuously perfused with artificial CSF (aCSF) containing the following additives (in $\mathrm{mm}$ ): $126 \mathrm{NaCl}, 2.5 \mathrm{KCl}, 2 \mathrm{CaCl}$, $26 \mathrm{NaHCO} 3,1.25 \mathrm{NaH}_{2} \mathrm{PO}_{4}, 2 \mathrm{MgSO}_{4}$, and 10 dextrose equilibrated with $95 \% \mathrm{O}_{2} / 5 \% \mathrm{CO}_{2}$, $\mathrm{pH}$ adjusted to 7.4. Patch electrodes were fabricated from borosilicate glass $(1.5 \mathrm{~mm}$ outer diameter; World Precision Instruments) with the P-2000 puller (Sutter Instruments). The tip resistance was in the range of 3-5 $\mathrm{M} \Omega$. The electrodes were filled with a pipette solution containing the following (in $\mathrm{mm}$ ): 120 potassium-gluconate, $20 \mathrm{KCl}, 2 \mathrm{MgCl}_{2}, 10 \mathrm{HEPES}, 0.1 \mathrm{EGTA}$, 2 ATP, and $0.25 \mathrm{GTP}$, pH adjusted to 7.25 with $\mathrm{KOH}$. The electrophysiology data were acquired using the ClampEx 10 software package (Molecular Devices). The data were analyzed offline using pClamp 10.

$R T-P C R$. Freshly frozen sciatic nerves and rat Schwann cells were processed for RNA extraction using an RNeasy Lipid Tissue Mini Kit or an RNeasy mini kit (Qiagen). Nerves from three to four animals were combined for lyses as one-sample. Total RNA $(1 \mu \mathrm{g})$ was synthesized to cDNA in $20 \mu \mathrm{l}$ of reaction mixture using an iScript cDNA synthesis kit 
Table 1. Primary antibodies used in the present study

\begin{tabular}{|c|c|c|c|c|}
\hline \multirow[b]{2}{*}{ Species } & \multirow[b]{2}{*}{ Antigen } & \multirow[b]{2}{*}{ Source and catalog \# (RRID) } & \multicolumn{2}{|l|}{ Dilution } \\
\hline & & & WB & IF \\
\hline Rabbit & ABCA1 & Novus Biologicals, NB400-105 (RRID: AB_10000630) & $1: 2000$ & $N / A$ \\
\hline Mouse & $A B C A 1$ & Novus Biologicals, NB100-2068 (RRID: AB_10002789) & N/A & $1: 100$ \\
\hline Rabbit & $\mathrm{ACC}$ & Abcam, ab45174 (RRID: AB_867475) & 1:2000 & $N / A$ \\
\hline Goat & ApoE & Millipore, AB947 (RRID: AB_2258475) & $1: 3000$ & $N / A$ \\
\hline Rabbit & ApoE & Abcam, ab20874 (RRID: AB_449883) & $\mathrm{N} / \mathrm{A}$ & 1:300 \\
\hline Mouse & c-Myc & Santa Cruz Biotechnology, sc-40 (RRID: AB_627268) & $1: 300$ & $N / A$ \\
\hline Mouse & Dystrophin & Sigma-Aldrich, D8043 (RRID: AB_259241) & $1: 2000$ & N/A \\
\hline Rabbit & GAPDH & Santa Cruz Biotechnology, FL-335 (RRID: AB_10167668) & $1: 5000$ & $N / A$ \\
\hline Mouse & GS15 & BD Biosciences, 610960 (RRID: AB_398273) & $\mathrm{N} / \mathrm{A}$ & $1: 200$ \\
\hline Rabbit & Laminin & Sigma-Aldrich, L9393 (RRID: AB_477163) & $1: 20,000$ & $N / A$ \\
\hline Rabbit & LAMP1 & Abcam, ab24170 (RRID: AB_775978) & 1:2000 & $\mathrm{N} / \mathrm{A}$ \\
\hline Rabbit & P62 & Abcam, ab91526 (RRID: AB_2050336) & $1: 1000$ & $N / A$ \\
\hline Rabbit & p75 & Abcam, ab8874 (RRID: AB_306827) & $1: 20,000$ & $1: 800$ \\
\hline Mouse & РHH3 & Millipore, 05-806 (RRID: AB_310016) & $1: 2000$ & $N / A$ \\
\hline Rabbit & PMP22 & Pareek et al., 1997 & $1: 3000$ & $\mathrm{~N} / \mathrm{A}$ \\
\hline Mouse & PMP22 & Santa Cruz Biotechnology, sc-515280 & $1: 500$ & $N / A$ \\
\hline Mouse (lgM) & PMP22 & NeoMarkers, $20-14$ & $\mathrm{~N} / \mathrm{A}$ & $1: 50$ \\
\hline Mouse & Rab8 & BD Biosciences, 610844 (RRID: AB_398163) & 1:1000 & $\mathrm{N} / \mathrm{A}$ \\
\hline Rat & Thy-1 & Abcam, ab3105 (RRID: AB_2287350) & $\mathrm{N} / \mathrm{A}$ & $1: 500$ \\
\hline Rabbit & Vinculin & Abcam, ab129002 (RRID: AB_11144129) & $1: 10,000$ & $\mathrm{~N} / \mathrm{A}$ \\
\hline Rabbit & $\beta$-actin & Abcam, ab75186 (RRID: AB_1280759) & $1: 10,000$ & $\mathrm{~N} / \mathrm{A}$ \\
\hline Rabbit & $\beta$-tubulin & Proteintech, 10094 (RRID: AB_2210695) & 1:1000 & $\mathrm{N} / \mathrm{A}$ \\
\hline
\end{tabular}

The isotype of all antibodies is IgG except when noted otherwise under "Species."

WB, Western blot; IF, immunofluorescence staining; N/A, not applicable.

(Bio-Rad). Real-time PCR was performed using TaqMan reagents and probes in microfluidic array cards (Applied Biosystems). Briefly, $100 \mathrm{ng}$ of cDNA in a $100 \mu \mathrm{l}$ reaction mixture was loaded into the reservoir of the microfluidic array cards and analyzed using QuantStudio software (Thermo Fisher Scientific). RPL32 mRNA was used as an internal control and the relative gene expression was determined using the $2^{-\Delta \Delta \mathrm{Ct}}$ method (Livak and Schmittgen, 2001).

Western blotting. Total nerve protein lysates were prepared by homogenization in modified radioimmunoprecipitation assay (RIPA) buffer ( $25 \mathrm{~mm}$ Tris, $150 \mathrm{~mm} \mathrm{NaCl}$, pH: 8.0, 1\% SDS, $0.5 \%$ sodium deoxycholate, $1 \%$ Triton X-100) supplemented with complete protease (Roche) and phosphatase (Sigma-Aldrich) inhibitors. Cultured mouse Schwann cells and mouse nerve fibroblasts were lysed in RIPA buffer with protease and phosphatase inhibitors. Protein concentrations were determined using a BCA (Pierce) assay kit and samples were resolved on polyacrylamide gels and transferred to nitrocellulose or PVDF membranes. After immunoblotting with primary antibodies and HRP-conjugated secondary antibodies (Cell Signaling Technology), blots were reacted with ECL reagent (Bio-Rad) and visualized via X-ray film or the ChemiDoc MP System (Bio-Rad). Primary antibodies used are shown in Table 1.

For PMP22 detection in lysates of cultured MNFs, we prepared detergent-insoluble protein fractions (Fortun et al., 2006). For endoglycosidase (endo $\mathrm{H}$ ) or $\mathrm{N}$-glycosidase digestions, $2 \mu \mathrm{g}$ of sciatic nerve lysates and $20 \mu \mathrm{g}$ of transfected cell lysates were treated with endo $\mathrm{H}$ or N-glycosidase (New England Biolabs) for 16 h (Pareek et al., 1997). For native gel electrophoresis, sciatic nerves from 6-week-old WT and PMP22 KO mice were minced under liquid nitrogen and lysed in Trisbuffered saline, pH 7.6, with protease inhibitors (Corona et al., 2016). After centrifugation at $7000 \mathrm{rpm}$ for $10 \mathrm{~min}$, supernatants were separated on $4-15 \%$ mini-protein TGX precast gels (Bio-Rad) under native conditions at $90 \mathrm{~V}$ for $3 \mathrm{~h}$. A high-molecular-weight calibration kit (GE Healthcare) was used to estimate protein migration. For semiquantitative analyses, densitometry was performed using ImageJ software and relative protein levels were determined after correction for a constitutive marker such as GAPDH, actin, or tubulin.

Co-IP assays. Rat Schwann cells and sciatic nerves were lysed in IP buffer $(0.15 \mathrm{M} \mathrm{NaCl}, 0.05 \mathrm{~m}$ Tris, 5 mm EDTA, pH 7.5, 1\% Triton X-100, $0.5 \%$ sodium deoxycholate, $0.1 \%$ SDS) supplemented with Complete Protease Inhibitor Cocktail (Roche) and $500 \mu \mathrm{M}$ phenylmethylsulfonyl fluoride (Sigma-Aldrich) (Amici et al., 2006). Lysate viscosity was reduced with benzonase nuclease (Novagen). After centrifugation, protein pellets were resolubilized in IP buffer containing 1\% (rat Schwann cells) or $2 \%$ (sciatic nerves) SDS and added back to the supernatant. The concentration of SDS in the final protein lysates was $0.25 \%$. The samples were then precleared with nonspecific rabbit serum and protein A-Sepharose (preblocked with 5\% BSA at room temperature; Sigma-Aldrich) for $30 \mathrm{~min}$ each, followed by incubation with rabbit anti-ABCA1 IgG antibody (Invitrogen) overnight at $4^{\circ} \mathrm{C}$. The antigen-antibody complexes were captured by the addition of protein A-Sepharose. Immunoprecipitates were eluted with 3\% SDS and 2\% $\beta$-mercaptoethanol-containing gel sample buffer and boiling for 10 min at $95^{\circ} \mathrm{C}$. Western blotting for PMP22, c-Myc, ABCA1, and dystrophin detections were performed as above.

Morphological studies. Sciatic nerves were collected from genotyped mice after $16 \mathrm{~h}$ of fasting. For lipid staining, longitudinal sciatic nerve sections were incubated with $0.5 \%$ Oil Red O solution (O0625; Sigma-Aldrich) at $60^{\circ} \mathrm{C}$ for $10 \mathrm{~min}$ followed by a brief immersion in Meyer's hematoxylin (MHS16; Sigma-Aldrich). Images were digitally captured from an Olympus BX43 upright microscope outfitted with an Olympus DP80 camera and exported to Adobe Photoshop CS3 for figure preparation.

Ultrastructural studies. Ultrastructural examination was conducted on nerves from WT and PMP22 KO mice after fixation in $2.5 \%$ glutaraldehyde in $0.1 \mathrm{M}$ phosphate buffer, $\mathrm{pH} 7.4$, for $24 \mathrm{~h}$ at $4^{\circ} \mathrm{C}$. Nerves were transferred to $0.1 \mathrm{M}$ phosphate buffer and processed for electron microscopy, as described previously (Amici et al., 2006). 
Fluorescent dye staining and immunolabeling. For filipin-cholesterol labeling, mouse Schwann cells were fixed with $4 \%$ paraformaldehyde for $10 \mathrm{~min}$. After rinsing in PBS, samples were incubated with $50 \mu \mathrm{g} / \mathrm{ml}$ filipin III (F4767; Sigma-Aldrich) in PBS for $1 \mathrm{~h}$ in the dark. For filipin costaining with GS15, after 4\% PFA fixation, cells were incubated with filipin $(50 \mu \mathrm{g} / \mathrm{ml})$ for $1 \mathrm{~h}$ before adding GS15 antibody. For CD11b and apoE costaining, sciatic nerve sections ( $8 \mu \mathrm{m}$ thickness) were fixed with $4 \%$ PFA for $1 \mathrm{~h}$ and permeabilized with ice-cold acetone for $2 \mathrm{~min}$. Thy- 1 and p75 costaining on mouse nerve fibroblasts was completed after fixation with $4 \%$ PFA for $10 \mathrm{~min}$ and permeabilization with ice-cold methanol for 5 min. For PMP22 or intracellular ABCA1 and PMP22 co-detection cells were permeabilized with $0.1 \%$ Triton X-100 for $10 \mathrm{~min}$ at room temperature; for cell surface staining, the permeabilization step was omitted. For ABCA1 and PMP22 costaining, sciatic nerve sections were permeabilized with ice-cold methanol for $5 \mathrm{~min}$. For ABCA1 staining on teased fibers and sectioned nerves, samples were fixed for 15-30 min with $4 \%$ PFA and permeabilized with $0.1 \%$ Triton X-100 for $15 \mathrm{~min}$. After blocking in 15\% normal goat serum for $1 \mathrm{~h}$ and incubating with primary antibodies overnight at $4^{\circ} \mathrm{C}$, bound primary antibodies were detected with appropriate fluorescent-dye conjugated secondary antibodies (Invitrogen). Hoechst dye (1:1000; Invitrogen) was applied to label nuclei, when indicated. Primary antibodies used are listed in Table 1. Coverslips were mounted on glass slides using Prolong Gold antifade (Invitrogen) and images were acquired on a Nikon A1RMPsi laserscanning confocal microscope. For CD11b-positive cell counting, nerve sections were observed under a Nikon Eclipse E800 microscope and five random areas were counted in a full-view field at $40 \times$ magnification.

Images were analyzed using Nikon NIS Elements Software version 4.40 or 4.51 . All colocalization studies were performed on backgroundreduced images after $2 \mathrm{D}$ deconvolution and Pearson correlation coefficient was determined (Adler and Parmryd, 2010; Dunn et al., 2011); Pearson coefficient $>0.7$ is considered a high-positive correlation ( $\mathrm{Mu}-$ kaka, 2012). For colocalization quantification, individual dots in the red and green channels were selected by a binary/mask setup and the numbers of dots were automatically calculated by the Nikon software. Dots in yellow (merged channel) were manually counted on individual images. Colocalization percentage was determined as the number of yellow dots/ number of red or green dots. For subcellular filipin intensity quantification, regions of interest (ROIs) of the whole cell were autodetected; ROIs of GS15-positive regions were selected after automatic binary detection by the Nikon software; ROIs of the plasma membrane were manually selected. For cell surface ABCA1 fluorescence intensity quantification, ROIs at the cell surface were automatically selected by the Nikon software.

LDL cholesterol uptake. Mouse Schwann cells were equilibrated for $18 \mathrm{~h}$ in DMEM-F12 medium supplemented with $10 \%$ lipoprotein-deficient FBS (Sigma-Aldrich) (Loregger et al., 2017). Cells were then treated with $10 \mu \mathrm{g} / \mathrm{ml}$ BODIPY-LDL (L3483; Invitrogen) for 3, 8, or $24 \mathrm{~h}$. After rinsing, cells were fixed, mounted, and imaged under a Nikon eclipse E800 microscopy system. Fluorescent intensity was determined via Nikon's NIS Elements software after autodetecting ROIs.

ApoE secretion and cholesterol efflux assays with pharmacological treatment paradigms. For apoE secretion assays, the conditioned medium was collected and concentrated using Ultra-4 centrifugal filter units (Amicon). The levels of secreted apoE and laminin were determined by Western blotting. At the time of media collection, cells from respective culture plates were lysed and processed for Western blotting with anti-ABCA1, LDLR, and apoE antibodies, as above.

Cholesterol efflux assays were conducted with ${ }^{3} \mathrm{H}$-cholesterol, as described previously (Dove et al., 2005). Briefly, mouse Schwann cells were plated at a density of $5 \times 10^{4}$ cells per well onto poly-L-lysine-coated 96-well plates and allowed to grow for $2 \mathrm{~d}$. Rat Schwann cells were plated at a density of $5 \times 10^{4}$ cells per well onto poly-L-lysine-coated 24-well culture plates and allowed to adhere overnight. Scrambled or PMP22 shRNA transfection was performed as described above. Cells were treated with DMEM or DMEM/F12 containing 1\% FBS, 1\% penicillin/streptomycin (pen/strep), 1\% Sandoz (58-03; Sigma-Aldrich), 100 $\mu \mathrm{g} / \mathrm{ml}$ acLDL prepared in-house, and $6 \mu \mathrm{Ci} / \mathrm{ml}{ }^{3} \mathrm{H}$-Cholesterol (NET139001MC; PerkinElmer) for $48 \mathrm{~h}$. Cells were then washed twice each with DMEM, 1\% BSA, 25 mM HEPES, and then with DMEM/ HEPES without BSA. After the washes, cells were maintained in the efflux medium overnight. For mouse Schwann cells, the efflux medium contained DMEM/F12, $1 \%$ Sandoz, 1\% pen/strep, and 1\% LPDS; the rat Schwann cell efflux medium contained DMEM, 1\% Sandoz, $1 \%$ pen/ strep, and no LPDS. Percentage efflux was calculated as the ratio of counts per minute in the efflux medium over the total combined counts per minute of the medium plus cells.

BODIPY-cholesterol efflux assays were performed as described previously (Sankaranarayanan et al., 2011) with minor modifications. Schwann cells, seeded in 48 -well plates $\left(1 \times 10^{5}\right.$ cells per well $)$ coated with poly-L-lysine and $5 \mu \mathrm{g} / \mathrm{ml}$ laminin, were incubated with sonicated labeling medium containing $0.017 \mathrm{~mm}$ BODIPY-cholesterol (Avanti Polar Lipids), $0.067 \mathrm{~mm}$ cholesterol (Sigma-Aldrich), and $3.33 \mathrm{~mm}$ methyl$\beta$-cyclodextrin (Sigma-Aldrich) in DMEM-F12 for $3 \mathrm{~h}$ at $37^{\circ} \mathrm{C}$. After 2 washes with DMEM-F12 (HEPES), cells were equilibrated in DMEMF12, $0.2 \%$ BSA for $1 \mathrm{~h}$ at $37^{\circ} \mathrm{C}$. After two rinses in FluoroBrite DMEM (Thermo Fisher Scientific), samples were maintained in FluoroBrite DMEM supplemented with 15 mM HEPES, 2 mM L-glutamine, 0.2\% BSA with or without pharmacological agents, and $20 \mu \mathrm{g} / \mathrm{ml}$ lipid-free human apoA-I (Calbiochem) for $18 \mathrm{~h}$. To increase ABCA1 activity, $0.1 \mathrm{~mm}$ 8-bromo-cAMP (8-br-cAMP; Sigma-Aldrich) was applied (Haidar et al., 2002); ABCA1 activity was inhibited with $2 \mu \mathrm{M}$ cyclosporine A (CsA) (Sigma-Aldrich) (Le Goff et al., 2004). After the indicated incubation periods, conditioned media were collected and filtered via 96-well 0.45 $\mu \mathrm{m}$ filter plates (VWR Scientific) by centrifuging at $2000 \mathrm{rcf}$ for $10 \mathrm{~min}$. Intracellular BODIPY-cholesterol was extracted with $1 \%$ cholic acid by shaking for $3 \mathrm{~h}$. Fluorescence intensities in the collected medium and in the corresponding cell lysates were determined by a BioTek Gen 5 reader (excitation $485 \mathrm{~nm}$, emission $516 \mathrm{~nm}$ ). Total cholesterol efflux was calculated by dividing the fluorescence intensity of the medium by the sum of fluorescence intensities of the medium plus the cell lysates. Background efflux in the absence of apoA-I acceptor was subtracted from total cholesterol efflux value (Shrestha et al., 2016).

Experimental design and statistical analyses. For all experiments, $n=$ $3-5$ independent cultures or tissues from $n=3-6$ genotyped male and female mice were used. For quantitative assays, all raw data were exported to GraphPad Prism software for statistical analyses. Statistical significance was determined based on $p$-values obtained from an unpaired two-tailed Student's $t$ test unless specified otherwise. $p<0.05$ was considered to be statistically significant. Graphs were plotted representing the mean \pm SEM.

\section{Results}

\section{Absence of PMP22 alters subcellular cholesterol distribution and the membrane properties of Schwann cells}

Previous studies identified perturbed lipid rafts and intracellular cholesterol retention in Schwann cells from PMP22 KO mice (Lee et al., 2014). To define the subcellular localization of cholesterol in the absence of PMP22, we performed high-resolution imaging of filipin-cholesterol with the Golgi marker GS15 (Fig. 1A). In Schwann cells from PMP22 KO mice, we detected prominent filipin-cholesterol signal in the perinuclear area, with reduced fluorescence intensity at the plasma membrane, compared with WT. Quantification of data from three independent experiments revealed a $\sim 44 \%$ increase $\left(t=3.1, p=0.0027, R^{2}=0.15\right.$, unpaired Student's $t$ test) in Golgi-associated filipin-cholesterol and a concomitant $\sim 32 \%$ reduction $\left(t=6.9, p<0.001, R^{2}=\right.$ 0.46 , unpaired Student's $t$ test) at the plasma membrane in PMP22-deficient cells (Fig. 1A,B). We confirmed the influence of PMP22 on cholesterol trafficking by shRNA knock-down in normal rat Schwann cells. Similar to the PMP22 KO cells, in cells expressing PMP22 shRNA-GFP, PMP22 immunoreactivity was reduced and cholesterol was prominent in the perinuclear region (Fig. 1C, top, arrows). Cells transfected with the scrambled shRNA-GFP and nontransfected cells displayed 
A
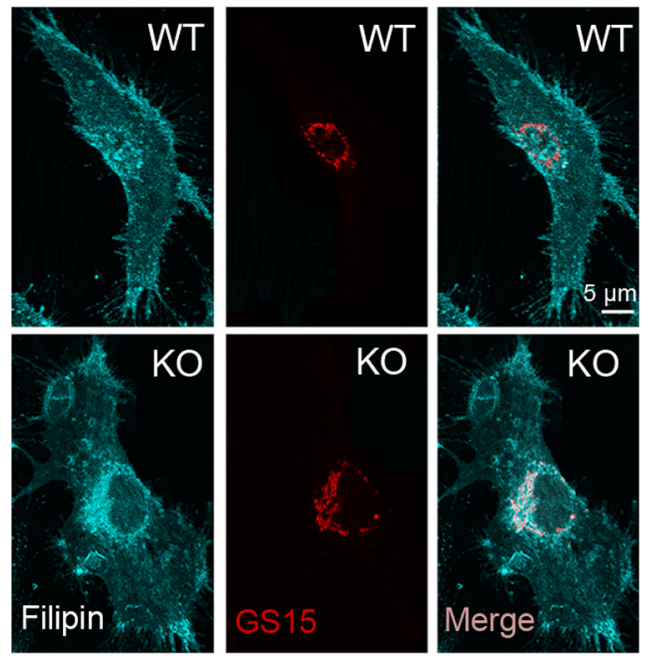

B

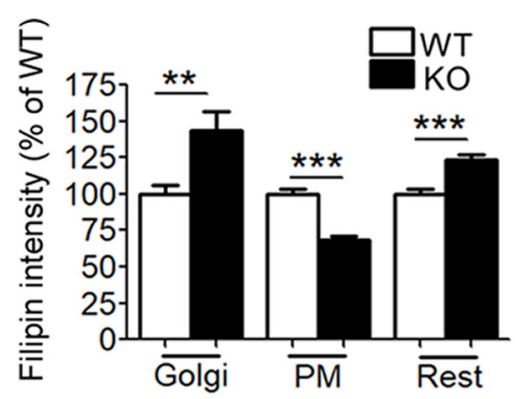

C
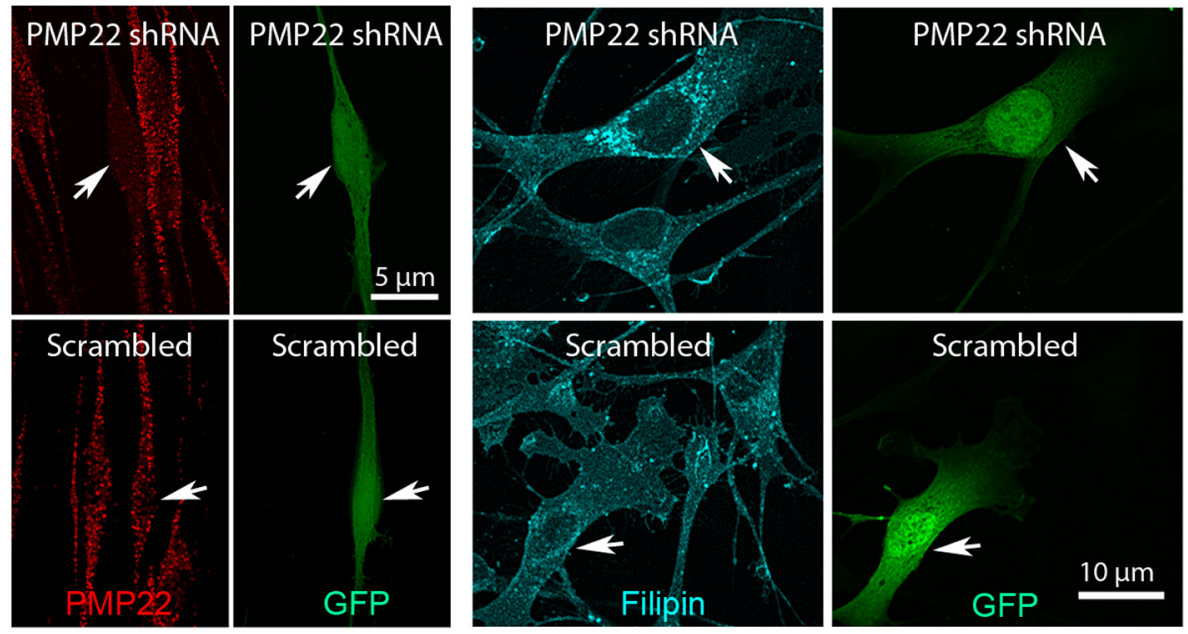

D
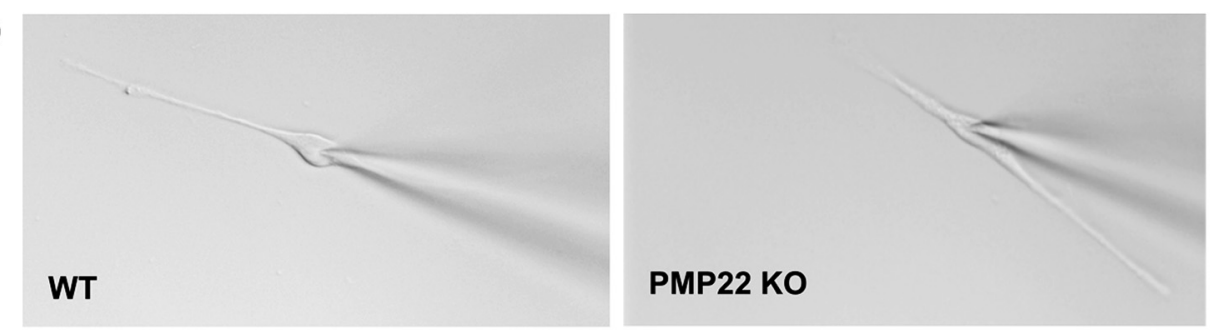

E

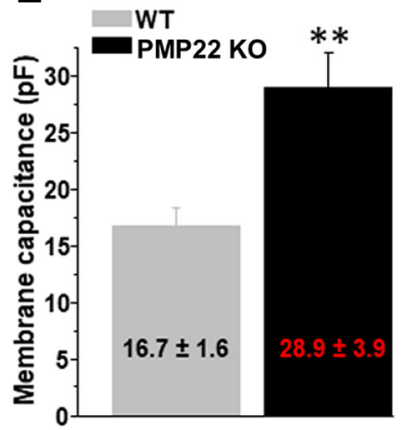

F

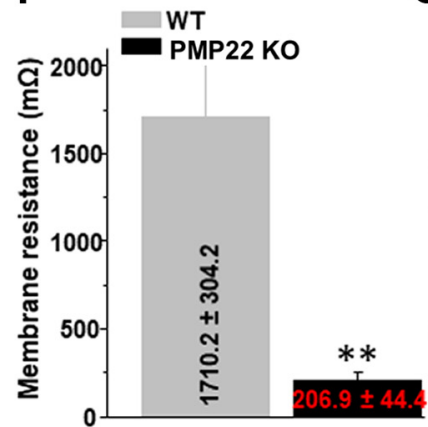

G

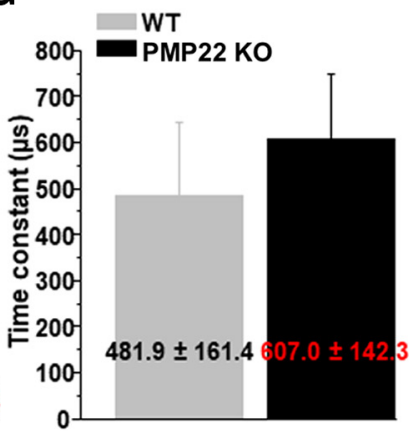

Figure 1. Intracellular cholesterol retention and perturbed membrane electrical properties in PMP22-deficient Schwann cells. $A, B$, Representative images of WT and PMP22 K0 mouse Schwann cells $(\boldsymbol{A})$ and quantification of filipin intensity $(\boldsymbol{B})$ in the Golgi and at the plasma membrane (PM) after costaining with anti-GS15 antibody ( $n=80$ cells each genotype). "Rest" indicates the rest of a cell minus the Golgi and PM. C, Representative images of PMP22 (red) and cholesterol (blue) localization after scrambled or PMP22 shRNA-GFP plasmid (green) transfection in rat Schwann cells. Arrows point to transfected cells. $\boldsymbol{D}$, Images depicting the location of patch pipettes relative to the cells subjected to current-clamp recordings. $\boldsymbol{E}-\boldsymbol{G}$, Current-clamp recordings of WT (gray bars) and PMP22 KO (black bars) mouse Schwann cells showing the membrane capacitance $(\boldsymbol{E})$, membrane resistance $(\boldsymbol{F})$, and time constant $(\boldsymbol{G})$ for each experimental group $(n=10$ cells per group from three independent replicates). For all experiments, values represent the mean \pm SEM. ${ }^{* *} p<0.01 ;{ }^{* *} p<0.001$, two-tailed Student's $t$ test. 
prominent, plasma-membrane-associated filipin-cholesterol (Fig. 1C, bottom).

Lipids, and cholesterol in particular, are known to affect the electrical properties of biological membranes (Stephens and Shinitzky, 1977; Tillman and Cascio, 2003; Starke-Peterkovic et al., 2006), which is of fundamental importance for myelin regulation of electrical properties of the neuronal membrane, and thus conduction. Therefore, we examined the functional consequences of the observed membrane cholesterol deficiency in PMP22 KO Schwann cells by whole-cell current-clamp recordings (Fig. $1 D-$ $G)$. As shown in Figure $1 E-G$, we found significantly increased membrane capacitance (WT $16.7 \pm 1.6 \mathrm{pF}$ vs PMP22 KO $28.9 \pm$ $3.9 \mathrm{pF}, t=4.1, p=0.0006, R^{2}=0.49$, two-tailed Student's $t$ tests) and decreased membrane resistance (WT $1710.2 \pm 304.2 \mathrm{~m} \Omega$ vs PMP22 KO $206.9 \pm 44.4 \mathrm{~m} \Omega, t=5.8, p<0.0001, R^{2}=0.65$, two-tailed Student's $t$ tests) in cells from PM22 KO mice. The increased membrane capacitance was unlikely the consequence of a larger cell volume because Schwann cells from PMP22 KO mice display shortened axial length and collapsed lamellipodia (Lee et al., 2014). There was no change in the time constant (WT $481.9 \pm 161.4 \mu \mathrm{s}$ vs PMP22 KO $607.0 \pm 142.3 \mu \mathrm{s}, t=0.7, p=0.5$, $R^{2}=0.026$, two-tailed Student's $t$ tests), probably due to the concomitant increased capacitance and decreased resistance. It is plausible that the reduction in membrane-associated cholesterol in the absence of PMP22 alters the biophysical properties of the Schwann cell membrane and has functional consequences that could be a key factor in impaired nerve conduction in PMP22-deficient animals and patients (Hong et al., 2003). These data serve as the first evidence of an important role for PMP22 in maintaining the electrical properties of the Schwann cell membrane.

\section{Lipid accumulation and altered expression of lipid- metabolism-related genes in nerves from PMP22 KO mice}

To determine the extent of cholesterol abnormalities in samples from PMP22 KO mice, we determined the expression of SREBPand LXR-regulated genes (Fig. 2A). In nerves from 6-week-old mice, RT-PCR analyses revealed a $48.6 \%$ decrease in fatty acid synthase (FAS) $(t=7.4, p=0.018$, two-tailed one-sample $t$ test $)$, a $72.2 \%$ decrease in low-density lipoprotein receptor $(L D L R)$ $(t=10.8, p=0.0084$, two-tailed one-sample $t$ test $)$, and a $64.0 \%$ decrease in HMG-Co-A reductase (HMG-CoA R) $(t=6.8, p=$ 0.02 , two-tailed one-sample $t$ test) expression in the absence of PMP22 compared with WT. Within the same samples, we detected a 3.2-fold increase in APOE ( $t=5.0, p=0.037$, two-tailed one-sample $t$ test $)$ and a 9.2-fold increase in $A B C A 1(t=5.3, p=$ 0.033 , two-tailed one-sample $t$ test) (Fig. 2A). Consistent with these results, we identified highly upregulated apoE ( 7.8 -fold, $t=$ 3.3, $p=0.016, R^{2}=0.65$, unpaired Student's $t$ test) and ABCA1 (9.8-fold, $t=7.3, p=0.0003, R^{2}=0.9$, unpaired Student's $t$ test) protein levels in affected nerves (Fig. $2 B, C$ ), whereas LDLR remained stable $\left(t=0.61, p=0.56, R^{2}=0.036\right.$, unpaired Student's $t$ test) (Fig. 2D,E).

To investigate lipid distribution in the nerves, we stained tissue sections with Oil Red O (Fig. $2 F$ ), a fat-soluble diazol dye that labels neutral lipids and cholesteryl esters in red (Mehlem et al., 2013). As shown in the representative images, compared with WT, PMP22 KO nerves accumulated neutral lipids in the endoneurial and perineurial regions (Fig. $2 F$, arrows). By ultrastructural examination, we identified lipid droplets (arrow) and vacuoles (V) within affected Schwann cells (Fig. 2G). Evaluation of 68 different Schwann cell profiles on images from nerve sections from three different PMP22 KO mice, 54 cells (79\%) con- tained lipid droplets. These lipid droplets were unlikely derived from myelin fragmentation and/or dysfunctional autophagy because we observed only moderate activation of autophagy-related protein in PMP22 KO nerves, including LAMP1 (2.5-fold, $t=$ 9.3, $\left.p<0.0001, R^{2}=0.93\right)$, p62 (1.6-fold, $t=4.8, p=0.0031$, $\left.R^{2}=0.79\right)$, and LC3 II/I (2.2-fold, $\left.t=6.9, p=0.0023, R^{2}=0.92\right)$ (Fig. 2H,I).

Because nerve fibroblasts and macrophages are potential sources for the elevated apolipoproteins and lipids (Stoll and Müller, 1986; Saada et al., 1995), we isolated Thy1-positive MNFs and analyzed the abundance of CD11b-reactive macrophages (Fig. 3). Although both ABCA1 and apoE appeared elevated in whole-protein lysates of cultured PMP22 KO nerve fibroblasts, this increase was not significant (ABCA1: WT $100 \pm 2.2 \%$ vs PMP22 KO: $145.1 \pm 24.6 \%, t=1.8, p=0.12, R^{2}=0.36$; apoE: WT $100 \pm 2.4 \%$ vs PMP22 KO: $127.2 \pm 15.6 \%, t=1.7, p=0.13$, $R^{2}=0.33$; unpaired Student's $t$ test) (Fig. $3 A, B$ ). The expression of PMP22 in cultured WT MNFs was low but detectable in detergent-insoluble membrane fractions (Fig. 3C). We monitored the number of Schwann cells in the fibroblast cultures by immunostaining for $\mathrm{p} 75$, which identified very few glial cells (Fig. $3 D)$. Next, we assessed the potential contribution of CD11bpositive macrophages to the elevated apoE in PMP22 KO nerves (Fig. $3 E-I$ ). We identified an $\sim 2.0$-fold increase in the occurrence of CD11b-positive macrophages (WT $5.8 \pm 1.3$ vs PMP22 KO $11.7 \pm 1.7 ; t=2.8, p=0.03, R^{2}=0.57$, unpaired Student's $t$ test), along with an $\sim 2.1$-fold increase of CD11b protein level in affected samples $\left(t=2.8, p=0.02, R^{2}=0.47\right.$, unpaired Student's $t$ test) (Fig. $3 E-G)$. Double immunolabeling with anti-apoE and $\mathrm{CD} 11 \mathrm{~b}$ antibodies revealed that macrophages were reactive for apoE (Fig. $3 \mathrm{H}$ ) and contributed to the elevated nerve apoE. However, macrophages were not prominent in the perineurial region (Fig. 3I), where we observed pronounced accumulation of lipid droplets (Fig. 2F). These results indicate that, compared with microphages and fibroblasts, Schwann cells are the predominantly affected cell type in PMP22 KO nerves that contribute to the observed dyslipidemia.

\section{ABCA1 deficiency causes elevated expression and compromised processing of PMP22}

Given the pronounced increase of ABCA1 in nerves from PMP22-deficient animals (Fig. 2), we examined samples from ABCA1 KO mice, which model Tangier disease (Aiello et al., 2003). By Western blot analyses, we studied the levels of myelinassociated glycoprotein (MAG), P0, and p75 in total sciatic nerve lysates from heterozygous and homozygous ABCA1-deficent mice (Fig. $4 A, B$ ). As shown on the blots and semiquantitative analyses, the levels of these key myelin proteins remained steady across the three genotypes (MAG: $F=0.76, p=0.50, R^{2}=0.16$; P0: $F=0.06, p=0.94, R^{2}=0.016 ; \mathrm{p} 75: F=0.55, p=0.60, R^{2}=$ 0.14; one-way ANOVA followed by the Tukey's post test). Schwann cell dedifferentiation and hyperproliferation have been observed in neuropathies (Niemann et al., 1999); therefore, we also determined the levels of phospho-histone $\mathrm{H} 3$ (PHH3), a mitotic marker. In nerves from heterozygous and homozygous ABCA1-deficient mice, PHH3 levels remained below detection, whereas hypertrophic phenotype was evident in PMP22 KO samples (Fig. 4C). In contrast to MAG, P0, and p75, nerves from 10 -month-old ABCA1 KO mice contained $\sim 1.53$-fold higher levels of PMP22 relative to WT, with an intermediate 1.37-fold increase in the heterozygous (HET) samples $(F=7.2, p=0.013$, $R^{2}=0.62$; one-way ANOVA followed by the Tukey's post test) (Fig. $4 D, E$ ). To determine the subcellular processing of the ele- 


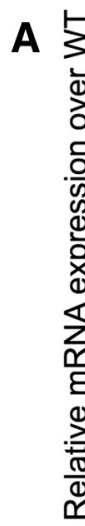

$\mathbf{F}$

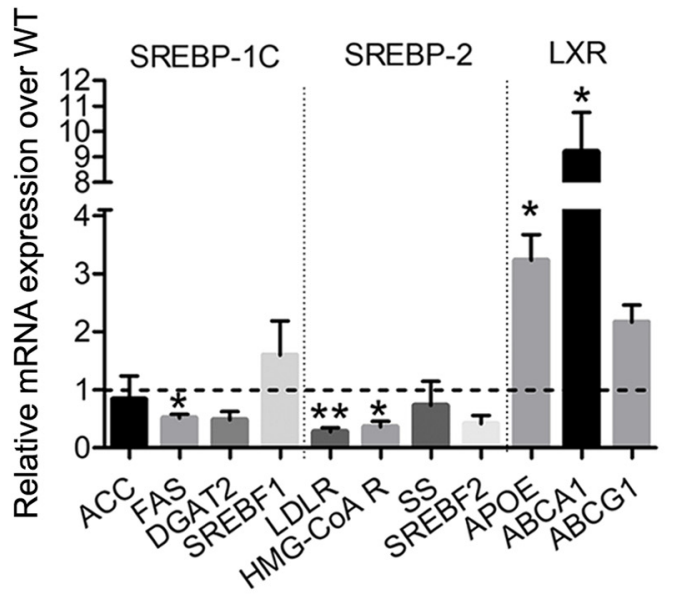

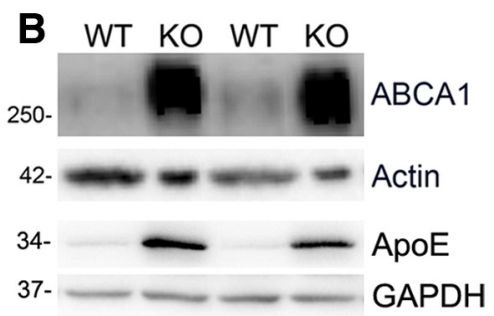

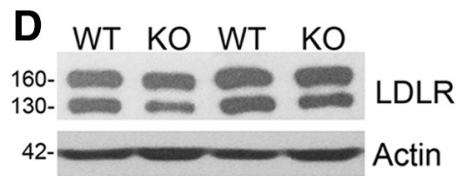

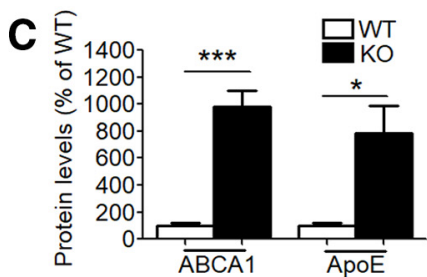

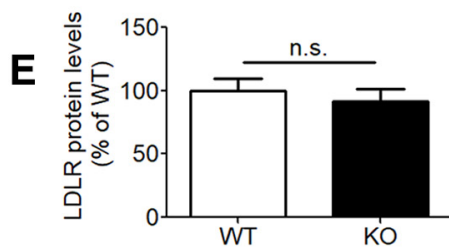

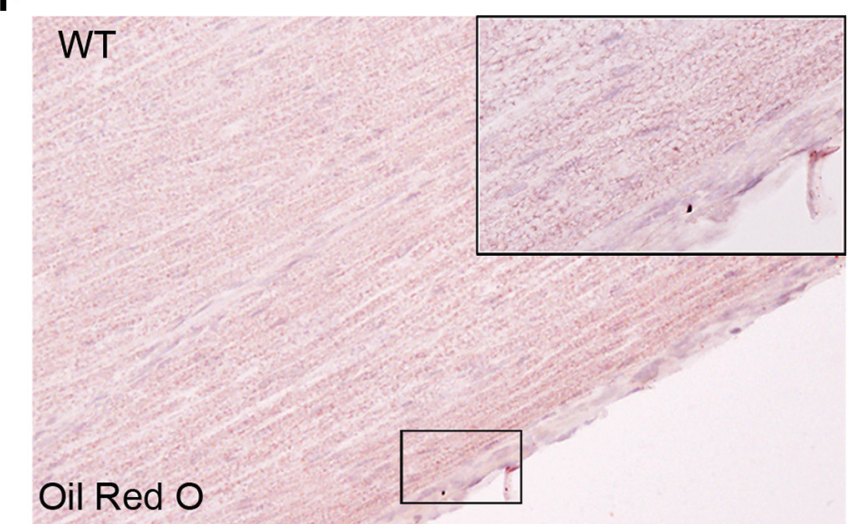

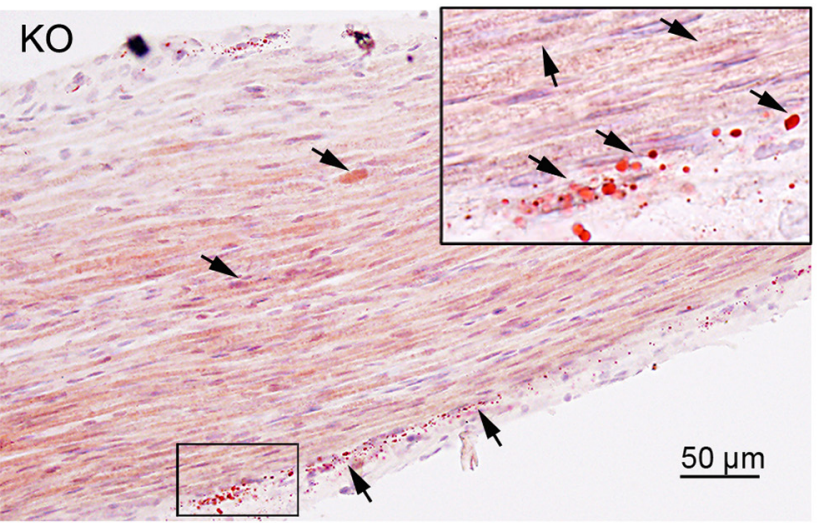

G
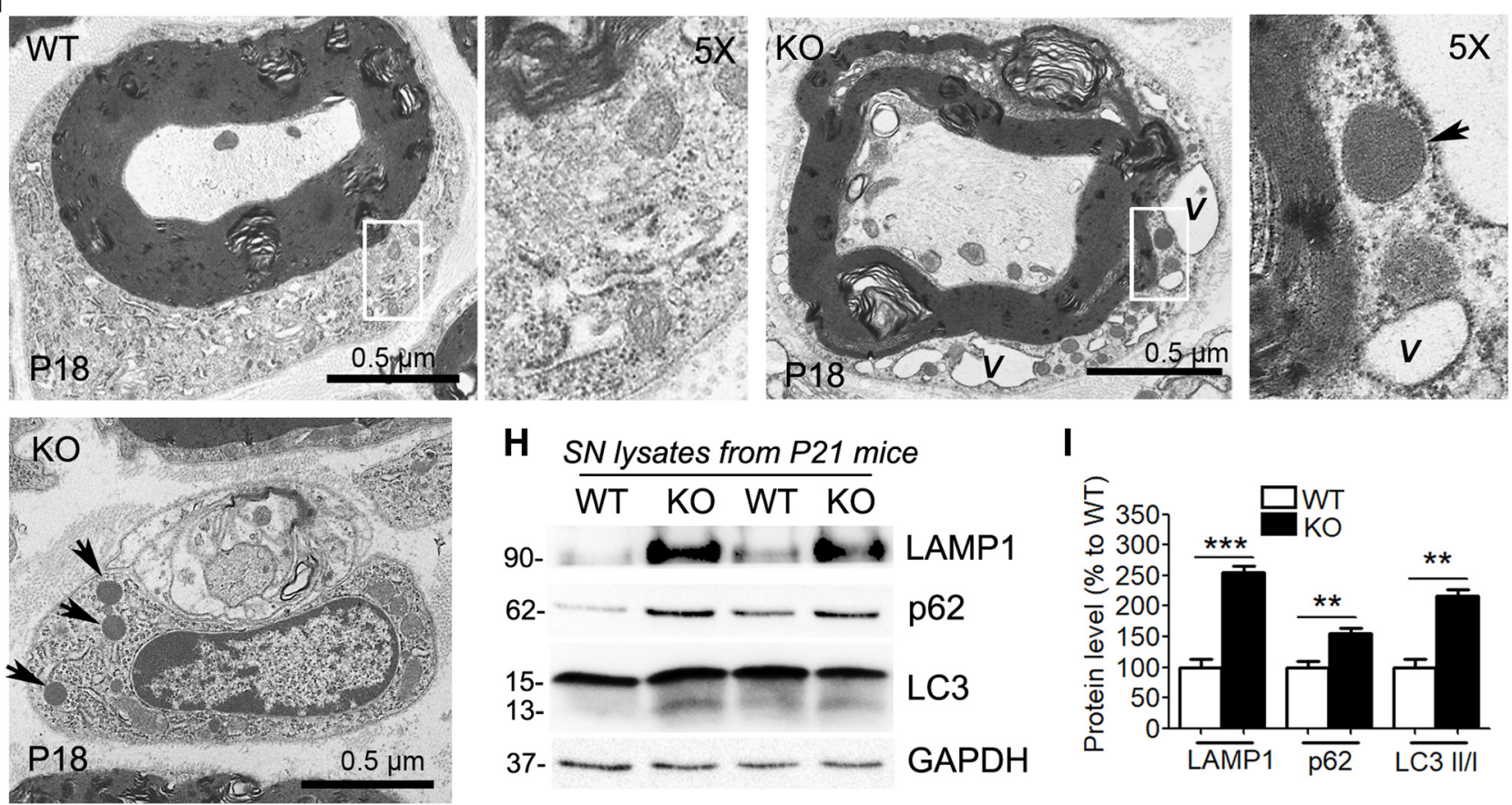

Figure 2. Lipid accumulation and altered expression of lipid-metabolism-related genes in peripheral nerves from PMP22 K0 mice. $A$, In the absence of PMP22, genes involved with cholesterol efflux (regulated by LXR/RXR) are increased, whereas genes linked to lipid synthesis (SREBP-1c and SREBP-2 pathways) are reduced ( $n=3$ independent experiments). RPL32 served as the internal control. $\boldsymbol{B}-\boldsymbol{E}$, Immunoblot detection $(\boldsymbol{B}, \boldsymbol{C})$ and quantification $(\boldsymbol{D}, \boldsymbol{E})$ of ABCA1 and apoE and LDLR in nerves from WT and PMP22 K0 mice. $\boldsymbol{F}$, 0il Red 0 staining detects accumulated neutral lipids in the perineurium and endoneurium (arrows) on longitudinal sections of PMP22 K0 nerves. Nuclei (purple) are stained with hematoxylin. $G$, Representative images from P18 sciatic nerves showing vacuoles (V) and lipid droplets (arrow) in PMP22 K0 Schwann cells. Boxed areas are magnified on the right of the panels. $\boldsymbol{H}, \boldsymbol{I}$, Immunoblot detection $(\boldsymbol{H})$ and quantification $(\boldsymbol{I})$ of autophagy markers LAMP1, p62, and LC3 in nerves from WT and PMP22 K0 mice. Actin and GAPDH are shown as protein-loading controls. Values represent the mean \pm SEM. ${ }^{*} p<0.05 ;{ }^{* *} p<0.01$; ${ }^{* * *} p<0.001$, n.s., non-significant, one-sample $t$ test or two-tailed Student's $t$ test. $\boldsymbol{B}-\boldsymbol{I}, n=3-6$ mice each genotype. 

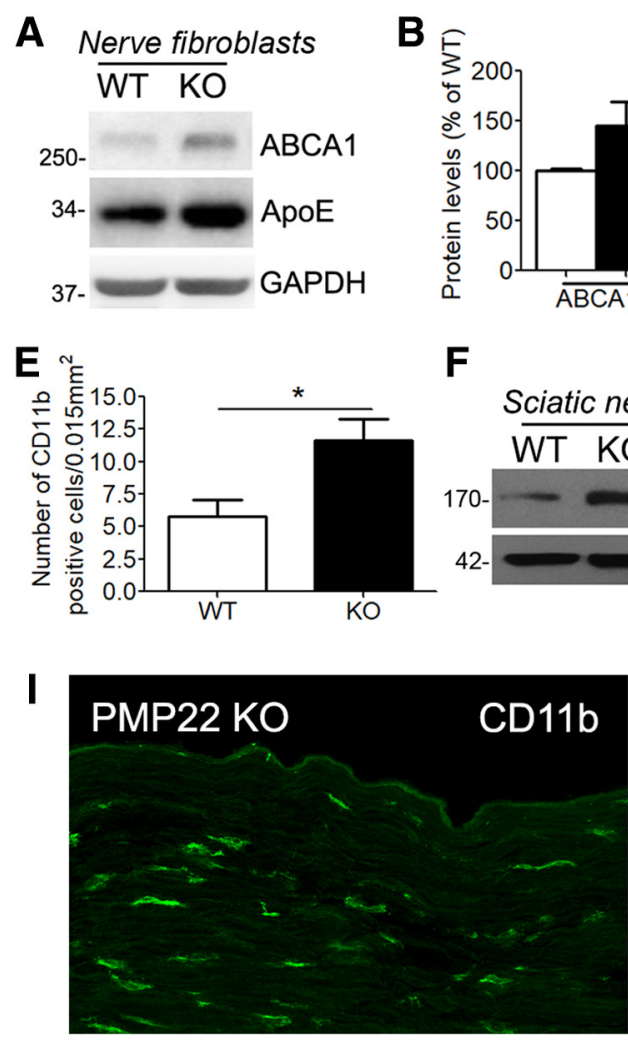
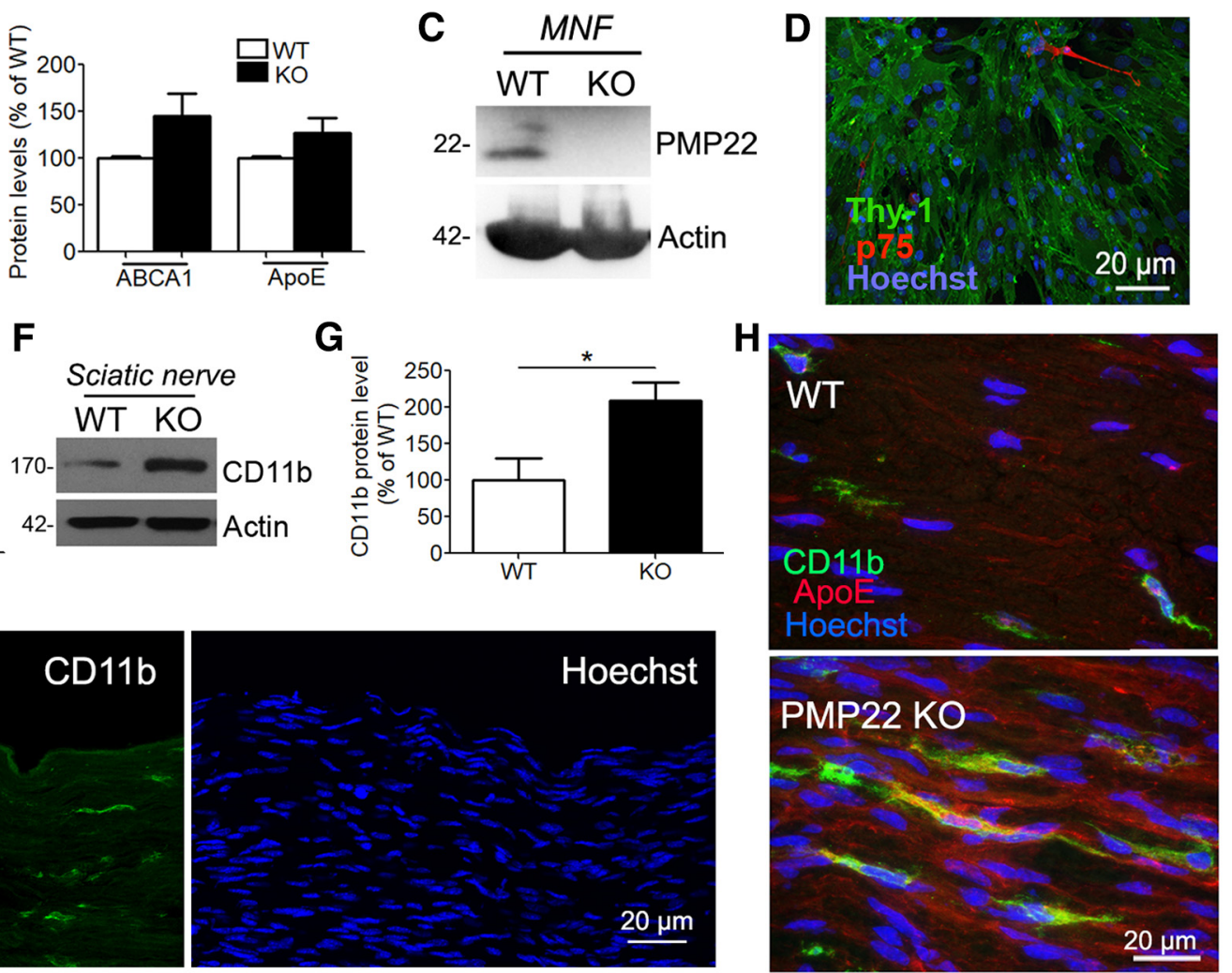

Figure 3. Nerve macrophages and fibroblasts make a limited contribution to lipid abnormalities in PMP22 K0 nerves. $\boldsymbol{A}, \boldsymbol{B}$, Immunoblot detection $(\boldsymbol{A})$ and quantification $(\boldsymbol{B})$ of $\mathrm{ABC}$ 1 and apoE in cultured nerve fibroblasts from WT and PMP22 KO mice. $\boldsymbol{C}$, Representative immunoblot showing the expression of PMP22 in WT MNFs. $\boldsymbol{D}$, Characterization of nerve fibroblast cultures by immunostaining for Thy- 1 and the Schwann cell marker P75. $\boldsymbol{E}$, Number of CD11b-positive cells in WT and PMP22 K0 nerve sections after immunostaining and counting. $\boldsymbol{F}$, $\boldsymbol{G}$, Immunoblot detection $(\boldsymbol{F})$ and quantification $(\boldsymbol{G})$ of CD11b in whole-nerve lysates from WT and PMP22 KO mice. Actin or GAPDH is shown as the protein-loading control. $\boldsymbol{H}$, C0-staining for CD11b and apoE showing macrophages positive for apoE. I, CD11b-positive macrophages are detected in the endoneurium of PMP22 K0 nerves. Nuclei are stained with Hoechst dye (blue). Data were collected from three to four independent culture preparations $(\boldsymbol{A}-\boldsymbol{D})$ or from four animals per genotype $(\boldsymbol{E}-\boldsymbol{I})$. Values represent the mean \pm SEM. ${ }^{*} p<0.05$, two-tailed Student's $t$ test.

vated PMP22 in the absence of ABCA1, we treated sciatic nerve lysates with endo H or N-glycosidase F (Pareek et al., 1993, 1997). Quantification of data from independent experiments identified a decrease in the endo H-resistant PMP22, with a corresponding increase in the endo $\mathrm{H}$-sensitive fraction (endo $\mathrm{H}$ resistant: WT $81.9 \pm 4.2 \%$ vs ABCA1 HET $62.7 \pm 7.8 \%$ vs ABCA1 KO $52.2 \pm$ $1.8 \% ; F=8.3, p=0.019, R^{2}=0.73$; one-way ANOVA followed by the Tukey's post test) (Fig. $4 F, G$ ). The elevated levels of endo $\mathrm{H}$-sensitive PMP22 in the absence of ABCA1 indicates slowed intracellular processing of the newly synthesized protein through the secretory pathway (Pareek et al., 1997). The overexpression and aberrant processing of PMP22 in the absence of ABCA1 (Fig. $4 D-G)$, together with the increase in ABCA1 in nerves from PMP22 KO mice (Fig. 2), suggest a functional relationship between these two integral membrane proteins. Because nerves from patients with Tangier disease are known to contain tomacula and accumulate lipids (Hobbs and Rader, 1999; Cai et al., 2006), we stained samples from ABCA1 KO mice with Oil Red $\mathrm{O}$ (Fig. $4 H$ ). As expected, nerve fibers of ABCA1 KO mice contained elevated levels of neutral lipids compared with WT (Fig. $4 H)$. Therefore, the absence of PMP22 or ABCA1 in Schwann cells results in similar pathologies, including accumulation of neutral lipids and formation of tomacula.

\section{ABCA1 and PMP22 are codistributed within nerves and Schwann cells \\ To further examine the connection between PMP22 and ABCA1, we analyzed the localization of the two proteins on single-plane}

confocal images of detergent-permeabilized, double-immunolabeled Schwann cells isolated from WT mice. As shown on the representative images (Fig. $5 A, B$ ), there was a pronounced association between ABCA1-like (red) and PMP22-like (green) signals, indicating intracellular colocalization. Calculation of a Pearson correlation coefficient of $0.75 \pm 0.01$ further supported significant colocalization between the two proteins (Dunn et al., 2011). To assess the degree of codistribution of PMP22 and ABCA1 at the plasma membrane, we performed cell surface immunolabeling. Single-plane confocal images and subsequent quantification of co-detection (yellow spots) determined a partial colocalization of the two proteins on the cell surface of a given WT mouse Schwann cell (Fig. 5C), with $33.5 \pm 5.3 \%$ of surface $\mathrm{ABCA} 1$ and $40.5 \pm 4.7 \%$ of surface PMP 22 colocalized. We next costained for ABCA1 and PMP22 in longitudinal sciatic nerve sections and observed colocalization within Schwann cells (arrow) and at the outer cell membrane (arrowheads). Based on the results from the double-immunolabeling experiments, we investigated a potential association between PMP22 and ABCA1 by co-IP in normal samples (Fig. 5E-G). Both ABCA1 and PMP22, or ABCA1 and PMP22-Myc, were identified within the total (T) protein homogenates and, upon IP with an anti-ABCA1 antibody, PMP22, or c-Myc, were detected in the pulldown fraction (Fig. $5 E-G$ ). As a control of specificity, PMP22 was absent in the anti-ABCA1 antibody pulldown from PMP22 KO nerves, whereas dystrophin, a known ABCA1-binding partner (Albrecht et al., 2008), was detected (Fig. 5H). Collectively, these data indicate that in normal nerves, a substantial fraction of PMP22 and 

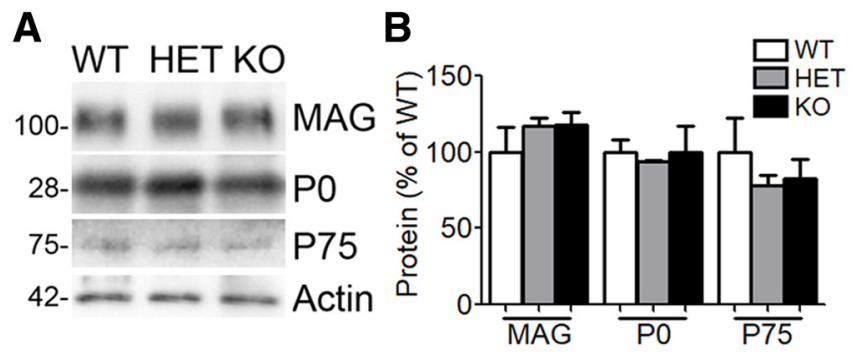

C

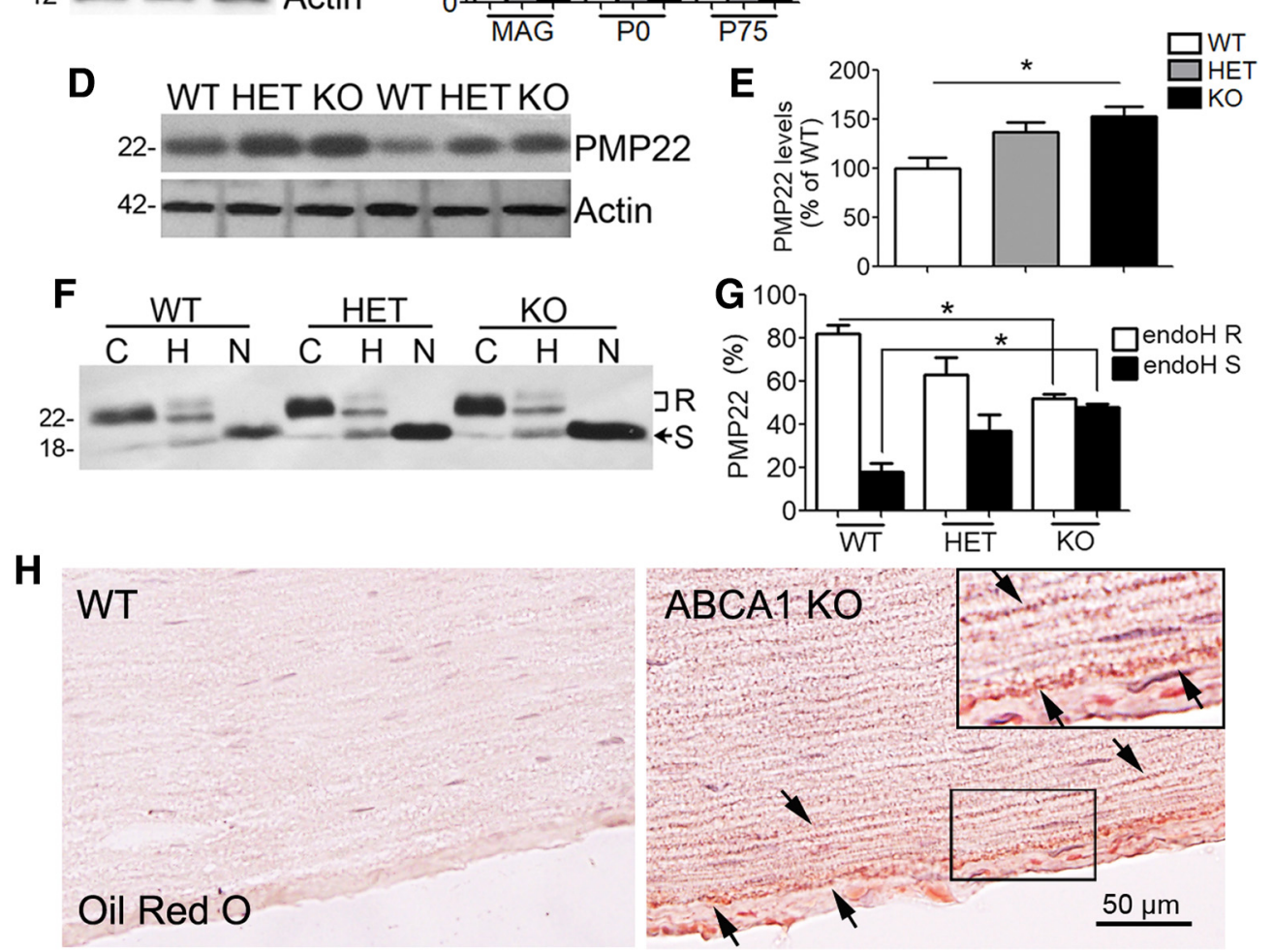

Figure 4. Elevated expression and altered processing of PMP22 in sciatic nerves from ABCA1-deficient mice. $\boldsymbol{A}, \boldsymbol{B}$, Immunoblot detection $(\boldsymbol{A})$ and quantification (B) of myelin proteins MAG, P0, and P75 in nerve samples from control (WT), heterozygous (HET), and homozygous (KO) ABCA1-deficient mice. C, Immunoblot detection of PHH3 from WT, ABCA1 HET, and ABCA1 K0 nerves. Nerve lysate from 6-week-old PMP22 K0 mice is shown as a positive control. $\boldsymbol{D}, \boldsymbol{E}$, Immunoblot detection (D) and quantification (E) of PMP22 in nerves from WT, ABCA1 HET, and ABCA1 K0 mice. Actin is shown as a protein-loading control. $\boldsymbol{F}, \boldsymbol{G}$, Immunoblot detection $(\boldsymbol{F})$ and quantification $(\boldsymbol{G})$ of PMP22 after incubation in buffer without enzyme (C), with endo $\mathrm{H}(\mathrm{H})$, or with N-glycosidase (N). A decrease in the endo $\mathrm{H}$ resistant (R) PMP22 and a corresponding increase in endo $\mathrm{H}$ sensitive $(\mathrm{S}$, arrow) PMP22 is detected in the absence of ABCA1 (G). $\boldsymbol{H}, 0$ il Red 0 staining detects accumulated neutral lipids in the perineurium and endoneurium (arrows) on longitudinal sections of $A B C A 1 \mathrm{KO}$ nerves. Results are from four to five mice per genotype. Values represent the mean $\pm \mathrm{SEM}$. ${ }^{*} p<$ 0.05, one-way ANOVA followed by the Tukey's post test.

ABCA1 proteins coexpress within Schwann cells and are codistributed at the plasma membrane.

\footnotetext{
ABCA1-dependent cholesterol efflux is compromised in the absence of PMP22

Given the observed relationship between PMP22 and ABCA1 (Figs. 2, 4, 5) and the aberrant distribution of cholesterol and lipids in the absence of PMP22 (Figs. 1,2), we tested cholesterol secretion by cells from WT and PMP22 KO mice (Fig. 6). Because apoE contributes to cellular cholesterol efflux and is co-secreted with cholesterol in vitro (Shanmugaratnam et al., 1997; Mahley et al., 2006), we analyzed apoE levels in Schwann-cell-conditioned media (Fig. 6A,B). Glial cells from PMP22 KO mice secreted $\sim 29.1 \%$ less apoE compared with WT $\left(t=2.5, p=0.047, R^{2}=\right.$ 0.51 , unpaired Student's $t$ test), whereas the abundance of laminin in the media was similar among the samples $(t=0.42$, $p=0.69, R^{2}=0.03$, unpaired Student's $t$ test). Immunoblot analyses on total protein lysates of the same cells detected elevated apoE ( $\sim 2.2$-fold, $t=3.4, p=0.029, R^{2}=0.74$, unpaired Student's $t$ test) and ABCA1 ( 1.5-fold, $t=6.6, p=0.0027, R^{2}=$ 0.92, unpaired Student's $t$ test) in the absence of PMP22 (Fig.
}

$6 C, D)$. Conversely, LDLR expression was similar between the normal and mutant cells $\left(t=0.0007, p=1.0, R^{2}=7.1 \times 10^{-8}\right.$, unpaired Student's $t$ test). Consistent with the unaltered expression of LDLR, cholesterol uptake of BODIPY-LDL through LDLR-mediated endocytosis (Loregger et al., 2017) was comparable between WT and PMP22 KO Schwann cells (Fig. 6E,F).

As a direct measure of cholesterol efflux from the Schwann cells, we loaded cells with ${ }^{3} \mathrm{H}$-cholesterol (Dove et al., 2005) and studied the efflux over $16 \mathrm{~h}$ (Fig. 6G). Quantification from independent cultures identified a significant impairment in cholesterol efflux from PMP22 KO Schwann cells compared with WT (WT $17.4 \pm 0.8 \%$ vs PMP22, KO $7.9 \pm 1.8 \% ; t=4.9, p=0.0081$, $R^{2}=0.86$, unpaired Student's $t$ test). To further substantiate the influence of PMP22 on ABCA1 function, we studied ABCA1mediated cholesterol efflux in the presence of lipid-free human apoA-I in normal rat Schwann cells when PMP22 was suppressed (Fig. 6H). Rat Schwann cells transfected with a PMP22 shRNA secreted $\sim 44 \%$ less ABCA1-dependent cholesterol compared with scrambled control $\left(t=3.2, p=0.018, R^{2}=0.63\right.$, unpaired Student's $t$ test) (Fig. $6 H$ ). In these transfection experiments, the level of PMP22 knock-down was $46 \pm 4 \%$ compared with scram- 
A

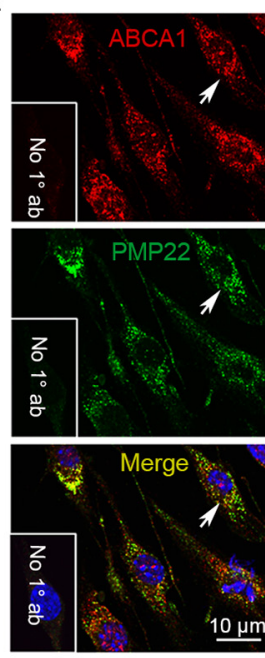

E

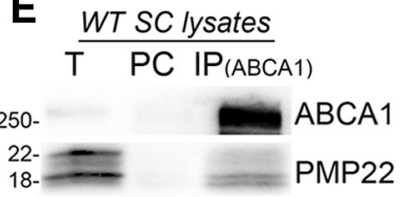

B

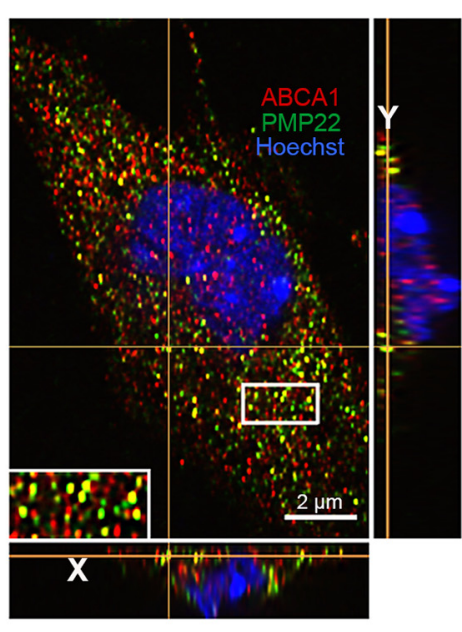

F PMP22-Myc Transfection $T \quad P C \quad I P(A B C A 1)$

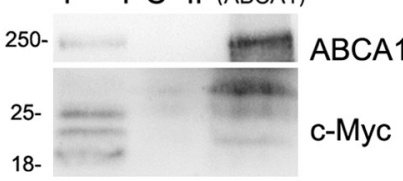

C
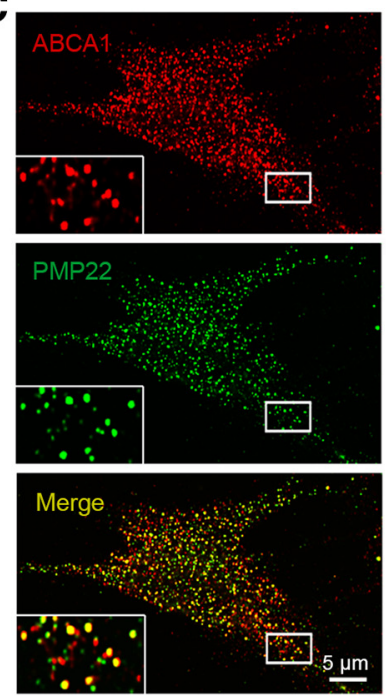

G

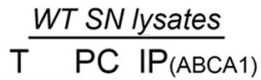
$250-$ ABCA1 $22-$ .

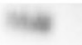

D
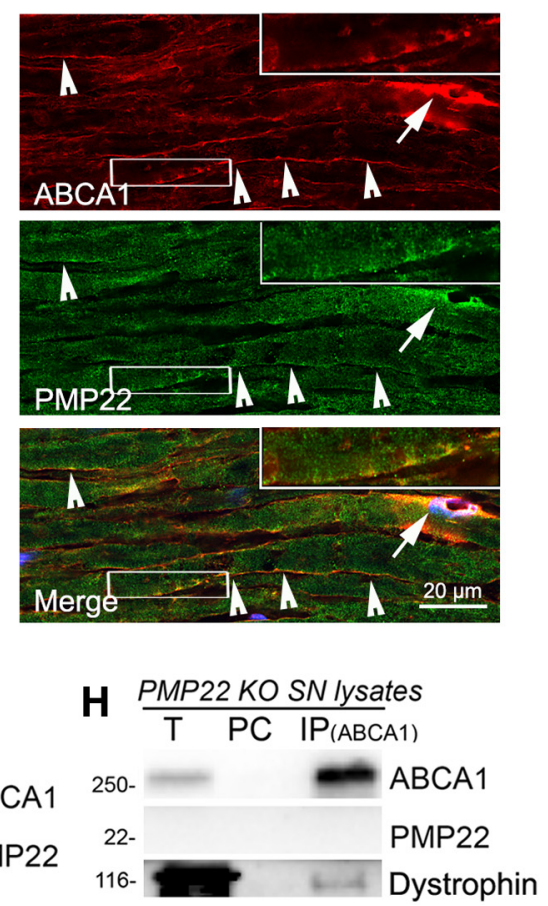

Figure 5. $A B C A 1$ and PMP22 are codistributed within Schwann cells. $A, B, A B C A 1$ and PMP22 costaining in cultured WT mouse Schwann cells after Triton X-100 permeabilization. Control for staining specificity with secondary antibody alone is shown in $\boldsymbol{A}$. Arrows point to the cell magnified in $\boldsymbol{B}$. $\boldsymbol{B}$, Representative high-magnification image after $Z$-stack (step size $=0.15 \mu \mathrm{m}$ ). Single $X Y$ plane in the middle, and XZ and YZ plane on the side display the colocalization of the two proteins (yellow) ( $n=150$ cells). C, Cell surface ABCA1 and PMP22 costaining in WT mouse Schwann cells revealing colocalization at the plasma membrane (yellow on merge) ( $n=100$ cells). D, ABCA1 and PMP22 costaining in longitudinal sections of WT mouse sciatic nerves (arrowheads). Arrow points to $S$ chwann cell body, with coexpression of the two proteins near the nucleus (blue). Boxed areas are magnified in the upright corner. $\boldsymbol{E}, \boldsymbol{F}, C$ oimmunoprecipitation of $A B C A 1$ and $P M P 22$ ( $\boldsymbol{E}$ ) or $A B C A 1$ and PMP22-Myc $(\boldsymbol{F})$ from WT rat Schwann cells or cells transfected with PMP22-Myc, respectively. $\mathbf{G}, \boldsymbol{H}$, Coimmunoprecipitation of ABCA1 and PMP22 from WT ( $\boldsymbol{G}$ ) and PMP22 K0 (H) mouse sciatic nerve (SN) homogenates. Dystrophin, a known ABCA1-binding partner, was precipitated as a positive control. Total protein lysate (T), preclear (PC), and IP are included for each experiment ( $n=3-5$ independent experiments).

bled. We also performed ABCA1-dependent BODIPY-cholesterol efflux assays with or without pharmacological modulation of ABCA1 (Fig. 6I-K). Under basal conditions, cholesterol efflux to apoA-I was $\sim 27.3 \%$ lower in PMP22 KO mouse Schwann cells compared with WT (WT 4.2 $\pm 0.4 \%$ vs PMP22 KO $3.0 \pm 0.2 \%$; $t=2.4, p=0.04, R^{2}=0.36$, unpaired Student's $t$ test). Upregulation of the expression and activity of ABCA1 with 8-bromocAMP (Haidar et al., 2002) significantly increased cholesterol efflux from both cell types, but to a lower extent from PMP22 KO cells (WT $6.0 \pm 0.5 \%$ vs PMP22 KO $3.8 \pm 0.2 \% ; t=4.7, p=$ $0.0012, R^{2}=0.71$, unpaired Student's $t$ test) (Fig. $\left.6 I-K\right)$. The immunosuppressant drug CsA blocks the endocytosis of membrane-associated ABCA1 and thus inhibits its activity (Le Goff et al., 2004). As expected, 18-h-long treatment with CsA increased the levels and blocked the activity of ABCA1 in WT cells; however, it had no effect on PMP22 KO cells (WT $2.4 \pm$ $0.4 \%$ vs PMP22 KO $2.6 \pm 0.2 \% ; t=0.56, p=0.59, R^{2}=0.03$, unpaired Student's $t$ test) (Fig. 6I-K). The atypical response of PMP22 KO cells to 8-bromo-cAMP and CsA indicates a reduction in functional ABCA1 at the plasma membrane.

\section{ABCA1 expression is reduced at the plasma membrane when} PMP22 is absent

To determine the levels of ABCA1 in the Schwann cell plasma membrane, we performed cell surface immunolabeling on nonpermeabilized cells (Fig. $7 A, B$ ). Confocal imaging and quantification detected an $\sim 25 \%$ decrease in ABCA1-like immunoreactivity on the glial cell surface in the absence of PMP22 $(t=3.5$, $p=0.0006, R^{2}=0.07$, unpaired Student's $t$ test), which likely contributed to the decreased cholesterol efflux (Fig. 6G-I,J). To confirm the influence of PMP22 on ABCA1 localization, we inhibited PMP22 in normal rat Schwann cells. As shown on the images, cells expressing PMP22 shRNA-GFP displayed reduced surface ABCA1-like fluorescence (Fig. 7C, arrow) compared with nontransfected cells (Fig. 7C, asterisk). Furthermore, ABCA1 was reduced at the Schwann cell membrane in PMP22 KO mouse nerves and this phenotype was evident on both nerve crosssections (Fig. 7D) and teased fibers (Fig. 7E).

Because Rab8 is known to facilitate cholesterol efflux and regulate the cell surface expression of ABCA1 (Linder et al., 2009), we tested Rab8 levels in WT and PMP22 KO nerves (Fig. $7 F, G$ ). Rab8 levels were increased $\left(\sim 1.5\right.$-fold, $t=2.7, p=0.034, R^{2}=$ 0.56 , unpaired Student's $t$ test) in sciatic nerves from PMP22 KO mice, likely as a compensatory mechanism to facilitate the presence and activity of ABCA1 at the cell surface. To further substantiate the relevance of the aberrant cholesterol efflux by PMP22-deficient Schwann cells, we examined the extent of apoE lipidation within whole sciatic nerve lysates using native gel electrophoresis (Corona et al., 2016). In agreement with the retention of cholesterol and ABCA1 within Schwann cells in the absence of PMP22 (Figs. $1,2,6,7 A-E)$, lipidated apoE in particles of the size of highdensity lipoproteins $(>8 \mathrm{~nm}$ or $140 \mathrm{kDa})$ was more abundant in PMP22 KO nerves relative to WT (Fig. $7 H$ ). Therefore, results from both in vitro and in vivo studies indicate that PMP22 is critical for lipid homeostasis in peripheral glial cells. 

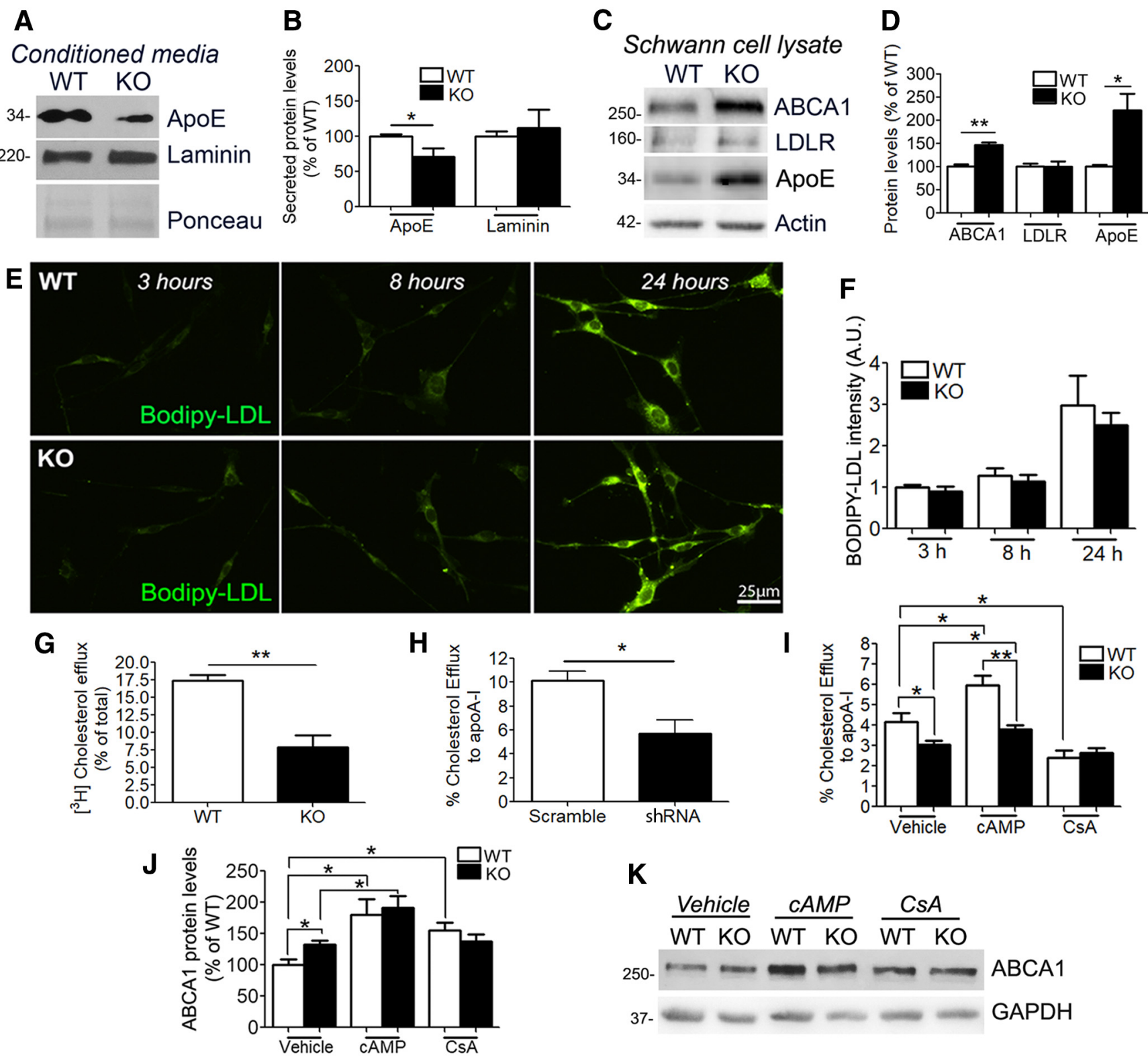

Figure 6. Decreased apoE secretion and cholesterol efflux in the absence of PMP22. $\boldsymbol{A}, \boldsymbol{B}$, Immunoblot detection $(\boldsymbol{A})$ and quantification $(\boldsymbol{B})$ of secreted apoE and laminin in the conditioned media of cultured mouse Schwann cells after 24 h. C, D, Immunoblot detection $(\boldsymbol{C})$ and quantification (D) of ABCA1, apoE, and LDLR in whole WT and PMP22 K0 Schwann cell lysates. Actin or Ponceau staining are shown as protein-loading controls. $\boldsymbol{E}, \boldsymbol{F}$, Visualization $(\boldsymbol{E})$ and quantification $(\boldsymbol{F})$ of BODIPY-LDL uptake by WT and PMP22 K0 mouse Schwann cells after 3,8 , and $24 \mathrm{~h}$ incubation times. $\mathbf{G},{ }^{3} \mathrm{H}$-cholesterol efflux to medium without apolipoprotein induction from WT and PMP22 KO mouse Schwann cells. $\boldsymbol{H},{ }^{3} \mathrm{H}$-cholesterol efflux to apoA1 in normal rat Schwann cells transfected with scrambled or PMP22 shRNA. I, BODIPY- cholesterol efflux to apoA1 in WT and PMP22 K0 mouse Schwann cells after treatments with 8-Br-cAMP (cAMP) or CSA of ABCA1.J, $K$, Quantification (J) and immunoblot detection $(\boldsymbol{K})$ of ABCA1 protein expression after treatments with vehicle (DMSO), 8-Br-CAMP (CAMP), or CsA. Results are representative of three to five independent experiments. Values represent the mean \pm SEM. ${ }^{*} p<0.05 ;{ }^{* *} p<0.01$, two-tailed Student's $t$ test.

\section{Discussion}

We sought to elucidate the role of PMP22 in Schwann cell biology and to better understand the subcellular events involved in the pathobiology of PMP22-linked hereditary neuropathies. Utilizing a previously characterized PMP22 KO mouse line (Amici et al., 2006), we discovered the critical requirement for PMP22 in maintaining the biophysical properties of the Schwann cell membrane and in cholesterol homeostasis. At the plasma membrane, the presence of PMP22 affects Schwann cell membrane resistance and capacitance, two key elements in myelin biology. Furthermore, by partnering with cholesterol, apoE, and ABCA1, PMP22 is involved in intracellular cholesterol trafficking and cholesterol efflux, which are central for the maintenance of PNS myelin integrity. Cholesterol not only serves as an essential building block of myelin, but it also affects the intracellular transport of the major PNS myelin protein P0 (Saher et al., 2009). Further studies will be required to determine whether PMP22 directly interacts with cholesterol; however, elegant in vitro studies have demonstrated the formation of compressed and cylindrically wrapped protein-lipid vesicles when purified PMP22 is reconstituted (Mittendorf et al., 2017). Therefore, our cellular and molecular studies described here, along with previously published work (Mittendorf et al., 2017), support the notion that altered expression of PMP22 causes peripheral myelin defects, in part through altering the organization and/or integrity of the glial membrane. 
A
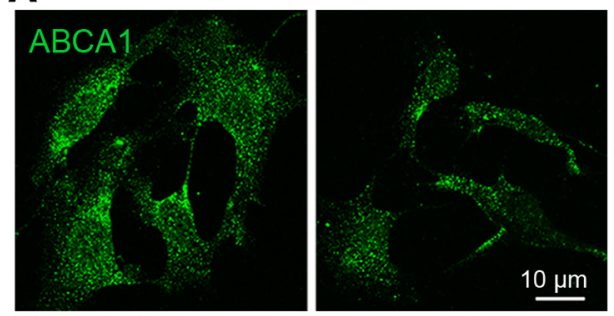

B

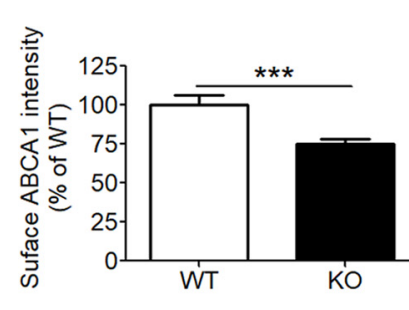

C

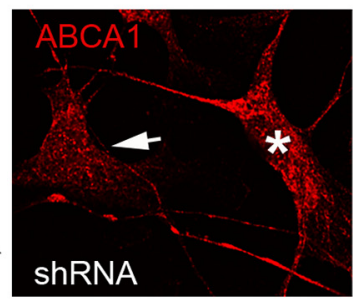

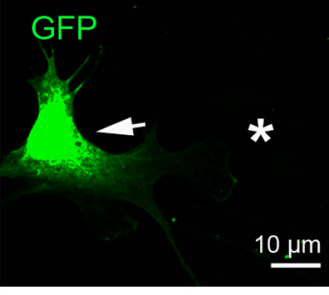

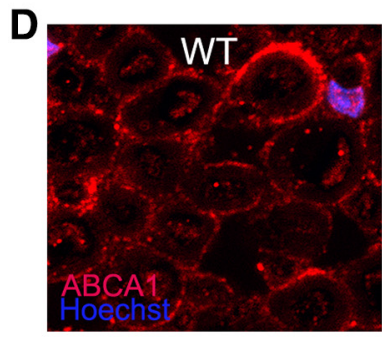

$\mathbf{F}$

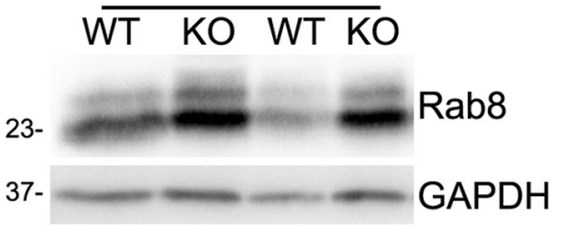

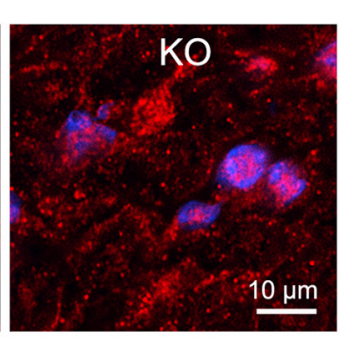

$10 \mu \mathrm{m}$

E
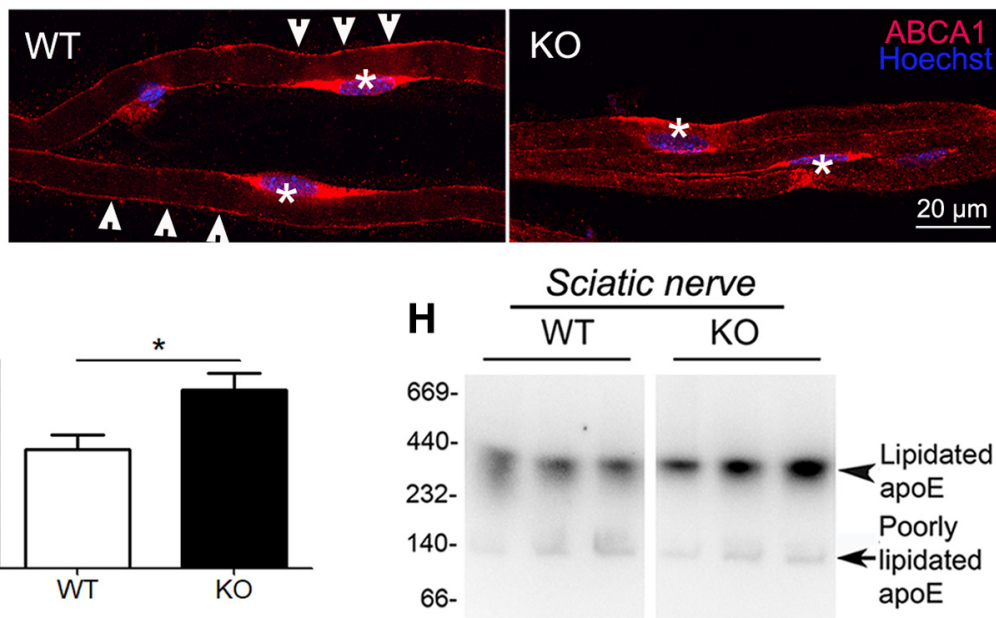

Figure 7. Reduced $A B C A 1$ expression at the plasma membrane in the absence of PMP22. $\boldsymbol{A}, \boldsymbol{B}$, Representative images of $A B C A 1$ immunoreactivity on the surface of WT and PMP22 K0 mouse Schwann cells $(\boldsymbol{A})$ and quantification of fluorescence intensity $(\boldsymbol{B})(n=90$ cells per genotype). $\boldsymbol{C}$, Representative images of $A B C A 1$ immunoreactivity on the surface of normal rat $S$ chwann cells after PMP22 shRNA-GFP transfection. Arrow points to a transfected cell as indicated by GFP expression. Asterisk marks a nontransfected cell. $\boldsymbol{D}, \boldsymbol{E}$, Representative images of ABCA1 localization in WT and PMP22 K0 nerve cross-sections (D) and teased nerve fibers ( $\boldsymbol{E}$ ). Arrowheads point to plasma-membrane-associated ABCA1 in WT nerves, and asterisks mark Schwann cell bodies. $\boldsymbol{F}, \boldsymbol{G}$, Immunoblot detection $(\boldsymbol{F})$ and quantification $(\boldsymbol{G})$ of Rab8 in lysates from WT and PMP22 K0 sciatic nerves. $\boldsymbol{H}$, Native immunoblot detection of lipidated (arrowheads) and poorly lipidated (arrows) apoE in whole sciatic nerve lysates. GAPDH or actin is shown as the protein-loading control. In $\boldsymbol{A}-\boldsymbol{C}$, Results are representative of three to five independent experiments; in $\boldsymbol{D}$ - $\boldsymbol{H}$, results are from three to four animals per genotype. Values represent the mean \pm SEM. ${ }^{*} p<0.05 ;{ }^{* * *} p<0.001$, two-tailed Student's $t$ test.

In the CNS, loss of ABCA1, a key regulator of cholesterol metabolism, is associated with functional and structural deficits (Karasinska et al., 2009). To date, the role of ABCA1 in peripheral nerve biology has not been investigated in detail, even though almost half of the patients with Tangier disease develop peripheral neuropathy (Hobbs and Rader, 1999). Here, we demonstrate a role for ABCA1 in Schwann cells and a functional linkage between ABCA1 and PMP22. In normal cells, PMP22 and ABCA1 are co-detected in subcellular compartments and at the plasma membrane. Our results from PMP22 KO cells indicate that loss of PMP22 results in compromised ABCA1-mediated cholesterol efflux with consequent accumulation of intracellular cholesterol, apoE, and ABCA1. The coordinated upregulation of ABCA1 and apoE in PMP22-deficient Schwann cells, along with the increase in PMP22 in ABCA1 KO nerves, support a functional relationship between these three proteins in cholesterol metabolism.

The nature of cholesterol dictates its essential role in myelin, the insulator of nerve axons. In addition to being a structural myelin component, cholesterol inhibits the activity of phospholipid-dependent $\mathrm{Na}^{+}$and $\mathrm{K}^{+}$channels and thus increases membrane resistance (Tobias et al., 1962; Papahadjopoulos et al., 1973). As a constituent of lipid rafts through interactions with sphingolipids, cholesterol reduces membrane fluidity and permeability (Barenholz, 2002). Cholesterol is rate-limiting for myelin membrane growth because the lack of cholesterol synthesis results in profound abnormalities in both the CNS and PNS (Saher et al., 2011). The mistrafficking of cholesterol can also lead to severe dysmyelination, such as seen in Niemann-Pick disease type C (NPC) (Qiao et al., 2018). NPC is characterized by the sequestration of cholesterol in lysosomes due to NPC gene mutations and associated hypoplasia in cerebellar white matter (Palmeri et al., 1994) and severe PNS myelin abnormalities, including vacuolization in the Schwann cell cytoplasm (Bagel et al., 2013). Therefore, aberrant expression of distinct genes involved with cholesterol metabolism leads to myelin defects, supporting the essential role for cholesterol in the glial membrane.

Myelin proteins with known cholesterol interaction include proteolipid protein (PLP) in the CNS and P0 in the PNS (Saher et al., 2009; Werner et al., 2013). Both of these glial proteins contain a cholesterol recognition amino acid consensus (CRAC) sequence, which is known to mediate the interaction of cholesterol with membrane proteins (Fantini and Barrantes, 2013). In oligodendrocytes, PLP, a tetraspan glycoprotein (Snipes et al., 1992) maintains cholesterol levels in the secretory pathway for myelin biogenesis (Werner et al., 2013). Our findings on the intracellular, Golgi-associated retention of cholesterol in PMP22 KO samples support a similar role for PMP22 in cholesterol secretion. In the PNS, the exit of P0 from the ER is dependent on cholesterol, which was discovered in cells with ablated squalene synthase (Saher et al., 2009). In the same model system, however, PMP22 was not retained in the ER, suggesting an independent mechanism for the transport of PMP22 and P0. PMP22 contains an evolutionary conserved CRAC motif in its fourth transmembrane domain (Gould et al., 2005; Sedzik et al., 2013) and mutations in this 
region have been linked to severe neuropathies (Ionasescu et al., 1997; Ikegami et al., 1998; Parman et al., 1999; Ohnishi et al., 2000; Maki et al., 2011). Therefore, given the intracellular retention of cholesterol in the absence of PMP22 shown here, it is plausible that, similar to PLP, PMP22 is key for the cholesterol trafficking from trans-Golgi to the plasma membrane. This hypothesis is supported by reduced levels of cholesterol secretion by PMP22 KO Schwann cells (Fig. 6).

A key role for PMP22 in lipid metabolism is reinforced by the observed induction of ABCA1 and apoE in PMP22 KO cells, likely through LXR activation. This hypothesis is supported by reports on the activation of LXR in various demyelinating conditions (Cermenati et al., 2013; Norrmén et al., 2014; Meffre et al., 2015), although in our samples, we did not detect an increase in LXR expression (data not shown). APOE, one of the genes regulated by LXR, has been linked to peripheral nerve injury and repair and is significantly upregulated in the absence of PMP22 (Ignatius et al., 1986; Lee et al., 2014). In agreement with our findings (Fig. 2A), the downregulation of SREBP pathways have been observed previously in other PMP22-linked neuropathic animal models (Vigo et al., 2005; Fledrich et al., 2012). The coordinated upregulation of ABCA1 and apoE and the associated decrease in some SREBP-1c and SREBP-2 dependent genes likely reflect counterregulatory maneuvers in cells reacting to abnormal cholesterol accumulation in PMP22 KO peripheral nerves (Lee et al., 2014). The identification of upstream and downstream signaling pathways mediating the observed phenotype will require further studies and may involve PI3K/AKT/mTOR (Goebbels et al., 2012).

ABCA1 is present in lipid rafts, where it interacts with apolipoproteins, free cholesterol, and sphingomyelin (Oram and Heinecke, 2005; Klappe et al., 2009; Phillips, 2018). Similarly, PMP22 is predicted to bind cholesterol through the cholesterol recognition (CRAC and CARC) motifs (Gould et al., 2005; Sedzik et al., 2013). Therefore, whereas it is currently unknown whether PMP22 and ABCA1 directly interact, it is conceivable that cholesterol acts as an intermediate in the association between these two proteins within lipid rafts. Our study shows that PMP22 and ABCA1 are codistributed in the plasma membrane and the absence of PMP22 impairs both ABCA1 trafficking and cholesterol efflux. This discovery is supported by the detection of ABCA1 in the Schwann cell membrane in association with dystrophin (Albrecht et al., 2008), a component of the dystrophin-glycoprotein complex. This dystrophin-glycoprotein complex binds laminin (Yamada et al., 1994), an extracellular matrix molecule that is complexed with PMP22 (Amici et al., 2006). In addition, ABCA1 directly associates with flotillin-1 (Bared et al., 2004), a constituent of lipid rafts whose distribution is perturbed in the nerves of PMP22 KO mice (Lee et al., 2014). Finally, the recognition of tomacula in ABCA1 $\mathrm{KO}$ nerves (Fig. $4 H$ ) and in a patient with Tangier disease (Cai et al., 2006) is another commonality between PMP22- and ABCA1-linked neuropathies (Lupski et al., 1993). Together, our findings support a synergistic functional connection between PMP22 and ABCA1 in cholesterol homeostasis in Schwann cells.

Better understanding of lipid metabolism in peripheral nerve biology has wide implications for neuropathies and provides critical information for the development of therapies. It was recently shown that defective cholesterol clearance limits remyelination in the aged CNS (Cantuti-Castelvetri et al., 2018) and could similarly play a critical role in the repair of demyelinated nerves in neuropathies. Indeed, an apoE mimetic peptide has been shown to benefit postcrush peripheral nerve repair (Li et al., 2010), likely through improving cholesterol and lipid reutilization during regeneration. In the cardiovascular field, ABCA1 has been considered as a therapeutic target (Oram, 2002; Kuntz et al., 2015) and such an approach could benefit patients with PMP22-linked peripheral nerve disorders such as CMT1A and HNPP. In related experiments, dietary cholesterol was shown to repair CNS myelin lesions, including in Pelizaeus-Merzbacher disease due to PLP overexpression (Saher et al., 2012; Berghoff et al., 2017). Considering the co-secretion of phospholipids and cholesterol through ABCA1-mediated efflux (Oram and Heinecke, 2005), it is conceivable that PMP22 misexpression disturbs phospholipid homeostasis, which could explain the effectiveness of phospholipid therapy in CMT1A rodents (Fledrich et al., 2018). Therefore, our findings provide significant new knowledge to advance our understanding of the connection between peripheral nerve biology and lipid metabolism and how this connection can be exploited for the development of therapies.

\section{References}

Adler J, Parmryd I (2010) Quantifying colocalization by correlation: the pearson correlation coefficient is superior to the Mander's overlap coefficient. Cytometry A 77:733-742.

Aiello RJ, Brees D, Francone OL (2003) ABCA1-deficient mice: insights into the role of monocyte lipid efflux in HDL formation and inflammation. Arterioscler Thromb Vasc Biol 23:972-980.

Albrecht DE, Sherman DL, Brophy PJ, Froehner SC (2008) The ABCA1 cholesterol transporter associates with one of two distinct dystrophinbased scaffolds in Schwann cells. Glia 56:611-618.

Amici SA, Dunn WA Jr, Murphy AJ, Adams NC, Gale NW, Valenzuela DM, Yancopoulos GD, Notterpek L (2006) Peripheral myelin protein 22 is in complex with alpha6beta4 integrin, and its absence alters the Schwann cell basal lamina. J Neurosci 26:1179-1189.

Archelos JJ, Roggenbuck K, Schneider-Schaulies J, Linington C, Toyka KV, Hartung HP (1993) Production and characterization of monoclonal antibodies to the extracellular domain of P0. J Neurosci Res 35:46-53.

Bagel JH, Sikora TU, Prociuk M, Pesayco JP, Mizisin AP, Shelton GD, Vite $\mathrm{CH}$ (2013) Electrodiagnostic testing and histopathologic changes confirm peripheral nervous system myelin abnormalities in the feline model of Niemann-Pick disease type C. J Neuropathol Exp Neurol 72:256-262.

Bared SM, Buechler C, Boettcher A, Dayoub R, Sigruener A, Grandl M, Rudolph C, Dada A, Schmitz G (2004) Association of ABCA1 with syntaxin 13 and flotillin-1 and enhanced phagocytosis in Tangier cells. Mol Biol Cell 15:5399-5407.

Barenholz Y (2002) Cholesterol and other membrane active sterols: from membrane evolution to "rafts". Prog Lipid Res 41:1-5.

Berghoff SA, Gerndt N, Winchenbach J, Stumpf SK, Hosang L, Odoardi F, Ruhwedel T, Böhler C, Barrette B, Stassart R, Liebetanz D, Dibaj P, Möbius W, Edgar JM, Saher G (2017) Dietary cholesterol promotes repair of demyelinated lesions in the adult brain. Nat Commun 8:14241.

Cai Z, Blumbergs PC, Cash K, Rice PJ, Manavis J, Swift J, Ghabriel MN, Thompson PD (2006) Paranodal pathology in Tangier disease with remitting-relapsing multifocal neuropathy. J Clin Neurosci 13:492-497.

Cantuti-Castelvetri L, Fitzner D, Bosch-Queralt M, Weil MT, Su M, Sen P, Ruhwedel T, Mitkovski M, Trendelenburg G, Lütjohann D, Möbius W, Simons M (2018) Defective cholesterol clearance limits remyelination in the aged central nervous system. Science 359:684-688.

Cermenati G, Brioschi E, Abbiati F, Melcangi RC, Caruso D, Mitro N (2013) Liver X receptors, nervous system, and lipid metabolism. J Endocrinol Invest 36:435-443.

Chance PF, Abbas N, Lensch MW, Pentao L, Roa BB, Patel PI, Lupski JR (1994) Two autosomal dominant neuropathies result from reciprocal DNA duplication/deletion of a region on chromosome 17. Hum $\mathrm{Mol}$ Genet 3:223-228.

Corona AW, Kodoma N, Casali BT, Landreth GE (2016) ABCA1 is necessary for bexarotene-mediated clearance of soluble amyloid beta from the hippocampus of APP/PS1 mice. J Neuroimmune Pharmacol 11:61-72.

Dove DE, Su YR, Zhang W, Jerome WG, Swift LL, Linton MF, Fazio S (2005) ACAT1 deficiency disrupts cholesterol efflux and alters cellular morphology in macrophages. Arterioscler Thromb Vasc Biol 25:128-134.

Dunn KW, Kamocka MM, McDonald JH (2011) A practical guide to eval- 
uating colocalization in biological microscopy. Am J Physiol Cell Physiol 300:C723-C742.

D’Urso D, Ehrhardt P, Müller HW (1999) Peripheral myelin protein 22 and protein zero: a novel association in peripheral nervous system myelin. J Neurosci 19:3396-3403.

Ekins S, Litterman NK, Arnold RJ, Burgess RW, Freundlich JS, Gray SJ, Higgins JJ, Langley B, Willis DE, Notterpek L, Pleasure D, Sereda MW, Moore A (2015) A brief review of recent Charcot-Marie-Tooth research and priorities. F1000Res 4:53.

Fantini J, Barrantes FJ (2013) How cholesterol interacts with membrane proteins: an exploration of cholesterol-binding sites including CRAC, CARC, and tilted domains. Front Physiol 4:31.

Fledrich R, Abdelaal T, Rasch L, Bansal V, Schütza V, Brügger B, Lüchtenborg C, Prukop T, Stenzel J, Rahman RU, Hermes D, Ewers D, Möbius W, Ruhwedel T, Katona I, Weis J, Klein D, Martini R, Brück W, Müller WC (2018) Targeting myelin lipid metabolism as a potential therapeutic strategy in a model of CMT1A neuropathy. Nat Commun 9:3025.

Fledrich R, Schlotter-Weigel B, Schnizer TJ, Wichert SP, Stassart RM, Meyer zu Hörste G, Klink A, Weiss BG, Haag U, Walter MC, Rautenstrauss B, Paulus W, Rossner MJ, Sereda MW (2012) A rat model of CharcotMarie-Tooth disease $1 \mathrm{~A}$ recapitulates disease variability and supplies biomarkers of axonal loss in patients. Brain 135:72-87.

Fortun J, Go JC, Li J, Amici SA, Dunn WA Jr, Notterpek L (2006) Alterations in degradative pathways and protein aggregation in a neuropathy model based on PMP22 overexpression. Neurobiol Dis 22:153-164.

Goebbels S, Oltrogge JH, Wolfer S, Wieser GL, Nientiedt T, Pieper A, Ruhwedel T, Groszer M, Sereda MW, Nave KA (2012) Genetic disruption of pten in a novel mouse model of tomaculous neuropathy. EMBO Mol Med 4:486-499.

Gould RM, Morrison HG, Gilland E, Campbell RK (2005) Myelin tetraspan family proteins but no non-tetraspan family proteins are present in the ascidian (Ciona intestinalis) genome. Biol Bull 209:49-66.

Haidar B, Denis M, Krimbou L, Marcil M, Genest J Jr (2002) cAMP induces ABCA1 phosphorylation activity and promotes cholesterol efflux from fibroblasts. J Lipid Res 43:2087-2094.

Heape A, Juguelin H, Fabre M, Boiron F, Cassagne C (1986) A quantitative developmental study of the peripheral nerve lipid composition during myelinogenesis in normal and trembler mice. Brain Res 390:181-189.

Hobbs HH, Rader DJ (1999) ABC1: connecting yellow tonsils, neuropathy, and very low HDL. J Clin Invest 104:1015-1017.

Hong YH, Kim M, Kim HJ, Sung JJ, Kim SH, Lee KW (2003) Clinical and electrophysiologic features of HNPP patients with $17 \mathrm{p} 11.2$ deletion. Acta Neurol Scand 108:352-358.

Horton JD, Goldstein JL, Brown MS (2002) SREBPs: activators of the complete program of cholesterol and fatty acid synthesis in the liver. J Clin Invest 109:1125-1131.

Ignatius MJ, Gebicke-Härter PJ, Skene JH, Schilling JW, Weisgraber KH, Mahley RW, Shooter EM (1986) Expression of apolipoprotein E during nerve degeneration and regeneration. Proc Natl Acad Sci U S A 83:11251129.

Ikegami T, Ikeda H, Aoyama M, Matsuki T, Imota T, Fukuuchi Y, Amano T, Toyoshima I, Ishihara Y, Endoh H, Hayasaka K (1998) Novel mutations of the peripheral myelin protein 22 gene in two pedigrees with DejerineSottas disease. Hum Genet 102:294-298.

Ionasescu VV, Searby CC, Ionasescu R, Chatkupt S, Patel N, Koenigsberger R (1997) Dejerine-Sottas neuropathy in mother and son with same point mutation of PMP22 gene. Muscle Nerve 20:97-99.

Johnson JS, Roux KJ, Fletcher BS, Fortun J, Notterpek L (2005) Molecular alterations resulting from frameshift mutations in peripheral myelin protein 22: implications for neuropathy severity. J Neurosci Res 82:743-752.

Joseph SB, Tontonoz P (2003) LXRs: new therapeutic targets in atherosclerosis? Curr Opin Pharmacol 3:192-197.

Juguelin H, Heape A, Boiron F, Cassagne C (1986) A quantitative developmental study of neutral lipids during myelinogenesis in the peripheral nervous system of normal and trembler mice. Brain Res 390:249-252.

Karasinska JM, Rinninger F, Lütjohann D, Ruddle P, Franciosi S, Kruit JK, Singaraja RR, Hirsch-Reinshagen V, Fan J, Brunham LR, Bissada N, Ramakrishnan R, Wellington CL, Parks JS, Hayden MR (2009) Specific loss of brain ABCA1 increases brain cholesterol uptake and influences neuronal structure and function. J Neurosci 29:3579-3589.

Keller H, Mahfoudi A, Dreyer C, Hihi AK, Medin J, Ozato K, Wahli W (1993)
Peroxisome proliferator-activated receptors and lipid metabolism. Ann N Y Acad Sci 684:157-173.

Klappe K, Hummel I, Hoekstra D, Kok JW (2009) Lipid dependence of ABC transporter localization and function. Chem Phys Lipids 161:57-64.

Kuntz M, Candela P, Saint-Pol J, Lamartinière Y, Boucau MC, Sevin E, Fenart L, Gosselet F (2015) Bexarotene promotes cholesterol efflux and restricts apical-to-basolateral transport of amyloid-beta peptides in an in vitro model of the human blood-brain barrier. J Alzheimers Dis 48: 849-862.

Lee S, Amici S, Tavori H, Zeng WM, Freeland S, Fazio S, Notterpek L (2014) PMP22 is critical for actin-mediated cellular functions and for establishing lipid rafts. J Neurosci 34:16140-16152.

Le Goff W, Peng DQ, Settle M, Brubaker G, Morton RE, Smith JD (2004) Cyclosporin A traps ABCAl at the plasma membrane and inhibits ABCA1-mediated lipid efflux to apolipoprotein A-I. Arterioscler Thromb Vasc Biol 24:2155-2161.

Li FQ, Fowler KA, Neil JE, Colton CA, Vitek MP (2010) An apolipoprotein E-mimetic stimulates axonal regeneration and remyelination after peripheral nerve injury. J Pharmacol Exp Ther 334:106-115.

Li J, Parker B, Martyn C, Natarajan C, Guo J (2013) The PMP22 gene and its related diseases. Mol Neurobiol 47:673-698.

Linder MD, Mäyränpää MI, Peränen J, Pietilä TE, Pietiäinen VM, Uronen RL, Olkkonen VM, Kovanen PT, Ikonen E (2009) Rab8 regulates ABCA1 cell surface expression and facilitates cholesterol efflux in primary human macrophages. Arterioscler Thromb Vasc Biol 29:883-888.

Livak KJ, Schmittgen TD (2001) Analysis of relative gene expression data using real-time quantitative PCR and the 2(-delta delta $\mathrm{C}(\mathrm{T})$ ) method. Methods 25:402-408.

Loregger A, Nelson JK, Zelcer N (2017) Assaying low-density-lipoprotein (LDL) uptake into cells. Methods Mol Biol 1583:53-63.

Lupski JR, Chance PF, Garcia CA (1993) Inherited primary peripheral neuropathies: molecular genetics and clinical implications of CMT1A and HNPP. JAMA 270:2326-2330.

Mahley RW, Huang Y, Weisgraber KH (2006) Putting cholesterol in its place: apoE and reverse cholesterol transport. J Clin Invest 116:12261229.

Maki T, Matsumoto R, Kohara N, Kondo T, Son I, Mezaki T, Nishino I, Ikeda A, Takahashi R (2011) Rippling is not always electrically silent in rippling muscle disease. Muscle Nerve 43:601-605.

Meffre D, Shackleford G, Hichor M, Gorgievski V, Tzavara ET, Trousson A, Ghoumari AM, Deboux C, Nait Oumesmar B, Liere P, Schumacher M, Baulieu EE, Charbonnier F, Grenier J, Massaad C (2015) Liver X receptors alpha and beta promote myelination and remyelination in the cerebellum. Proc Natl Acad Sci U S A 112:7587-7592.

Mehlem A, Hagberg CE, Muhl L, Eriksson U, Falkevall A (2013) Imaging of neutral lipids by oil red $\mathrm{O}$ for analyzing the metabolic status in health and disease. Nat Protoc 8:1149-1154.

Mittendorf KF, Marinko JT, Hampton CM, Ke Z, Hadziselimovic A, Schlebach JP, Law CL, Li J, Wright ER, Sanders CR, Ohi MD (2017) Peripheral myelin protein 22 alters membrane architecture. Sci Adv 3:e1700220.

Mukaka MM (2012) Statistics corner: a guide to appropriate use of correlation coefficient in medical research. Malawi Med J 24:69-71.

Niemann S, Sereda MW, Rossner M, Stewart H, Suter U, Meinck HM, Griffiths IR, Nave KA (1999) The "CMT rat": peripheral neuropathy and dysmyelination caused by transgenic overexpression of PMP22. Ann N Y Acad Sci 883:254-261.

Norrmén C, Figlia G, Lebrun-Julien F, Pereira JA, Trötzmüller M, Köfeler HC, Rantanen V, Wessig C, van Deijk AL, Smit AB, Verheijen MH, Rüegg MA, Hall MN, Suter U (2014) mTORC1 controls PNS myelination along the mTORC1-RXRgamma-SREBP-lipid biosynthesis axis in Schwann cells. Cell Rep 9:646-660.

Notterpek L, Ryan MC, Tobler AR, Shooter EM (1999) PMP22 accumulation in aggresomes: implications for CMT1A pathology. Neurobiol Dis 6:450-460.

Ohnishi A, Yamamoto T, Izawa K, Yamamori S, Takahashi K, Mega H, Jinnai K (2000) Dejerine-sottas disease with a novel de novo dominant mutation, Ser $149 \mathrm{Arg}$, of the peripheral myelin protein 22. Acta Neuropathol 99:327-330

Oram JF (2002) ABCA1 as a new therapeutic target for treating cardiovascular disease. Drug News Perspect 15:24-28.

Oram JF, Heinecke JW (2005) ATP-binding cassette transporter A1: a cell 
cholesterol exporter that protects against cardiovascular disease. Physiol Rev 85:1343-1372.

Palmeri S, Battisti C, Federico A, Guazzi GC (1994) Hypoplasia of the corpus callosum in Niemann-Pick type C disease. Neuroradiology 36:20-22.

Papahadjopoulos D, Cowden M, Kimelberg H (1973) Role of cholesterol in membranes. effects on phospholipid-protein interactions, membrane permeability and enzymatic activity. Biochim Biophys Acta 330:8-26.

Pareek S, Suter U, Snipes GJ, Welcher AA, Shooter EM, Murphy RA (1993) Detection and processing of peripheral myelin protein PMP22 in cultured Schwann cells. J Biol Chem 268:10372-10379.

Pareek S, Notterpek L, Snipes GJ, Naef R, Sossin W, Laliberté J, Iacampo S, Suter U, Shooter EM, Murphy RA (1997) Neurons promote the translocation of peripheral myelin protein 22 into myelin. J Neurosci $17: 7754-7762$.

Parman Y, Planté-Bordeneuve V, Guiochon-Mantel A, Eraksoy M, Said G (1999) Recessive inheritance of a new point mutation of the PMP22 gene in Dejerine-Sottas disease. Ann Neurol 45:518-522.

Phillips MC (2018) Is ABCA1 a lipid transfer protein? J Lipid Res 59:749-763.

Qiao L, Yang E, Luo J, Lin J, Yan X (2018) Altered myelination in the Niemann-Pick type C1 mutant mouse. Histol Histopathol 33:1311-1321.

Rao S, Morales AA, Pearse DD (2015) The comparative utility of viromer RED and lipofectamine for transient gene introduction into glial cells. Biomed Res Int 2015:458624.

Saada A, Dunaevsky-Hutt A, Aamar A, Reichert F, Rotshenker S (1995) Fibroblasts that reside in mouse and frog injured peripheral nerves produce apolipoproteins. J Neurochem 64:1996-2003.

Saher G, Brügger B, Lappe-Siefke C, Möbius W, Tozawa R, Wehr MC, Wieland F, Ishibashi S, Nave KA (2005) High cholesterol level is essential for myelin membrane growth. Nat Neurosci 8:468-475.

Saher G, Quintes S, Möbius W, Wehr MC, Krämer-Albers EM, Brügger B, Nave KA (2009) Cholesterol regulates the endoplasmic reticulum exit of the major membrane protein $\mathrm{P} 0$ required for peripheral myelin compaction. J Neurosci 29:6094-6104.

Saher G, Quintes S, Nave KA (2011) Cholesterol: a novel regulatory role in myelin formation. Neuroscientist 17:79-93.

Saher G, Rudolphi F, Corthals K, Ruhwedel T, Schmidt KF, Löwel S, Dibaj P, Barrette B, Möbius W, Nave KA (2012) Therapy of pelizaeusmerzbacher disease in mice by feeding a cholesterol-enriched diet. Nat Med 18:1130-1135.

Sankaranarayanan S, Kellner-Weibel G, de la Llera-Moya M, Phillips MC, Asztalos BF, Bittman R, Rothblat GH (2011) A sensitive assay for ABCA1-mediated cholesterol efflux using BODIPY-cholesterol. J Lipid Res 52:2332-2340.

Saporta MA, Katona I, Zhang X, Roper HP, McClelland L, Macdonald F, Brueton L, Blake J, Suter U, Reilly MM, Shy ME, Li J (2011) Neuropathy in a human without the PMP22 gene. Arch Neurol 68:814-821.

Sedzik J, Jastrzebski JP, Ikenaka K (2013) Sequence motifs of myelin membrane proteins: towards the molecular basis of diseases. J Neurosci Res 91:479-493.

Shanmugaratnam J, Berg E, Kimerer L, Johnson RJ, Amaratunga A, Schreiber BM, Fine RE (1997) Retinal Müller glia secrete apolipoproteins E and J which are efficiently assembled into lipoprotein particles. Brain Res Mol Brain Res 50:113-120.
Shimano H, Horton JD, Hammer RE, Shimomura I, Brown MS, Goldstein JL (1996) Overproduction of cholesterol and fatty acids causes massive liver enlargement in transgenic mice expressing truncated SREBP-1a. J Clin Invest 98:1575-1584.

Shrestha E, Hussein MA, Savas JN, Ouimet M, Barrett TJ, Leone S, Yates JR 3rd, Moore KJ, Fisher EA, Garabedian MJ (2016) Poly(ADP-ribose) polymerase 1 represses liver $\mathrm{X}$ receptor-mediated ABCA1 expression and cholesterol efflux in macrophages. J Biol Chem 291:11172-11184.

Snipes GJ, Suter U, Welcher AA, Shooter EM (1992) Characterization of a novel peripheral nervous system myelin protein (PMP-22/SR13). J Cell Biol 117:225-238.

Starke-Peterkovic T, Turner N, Vitha MF, Waller MP, Hibbs DE, Clarke RJ (2006) Cholesterol effect on the dipole potential of lipid membranes. Biophys J 90:4060-4070.

Stephens CL, Shinitzky M (1977) Modulation of electrical activity in Aplysia neurones by cholesterol. Nature 270:267-268.

Stoll G, Müller HW (1986) Macrophages in the peripheral nervous system and astroglia in the central nervous system of rat commonly express apolipoprotein $\mathrm{E}$ during development but differ in their response to injury. Neurosci Lett 72:233-238.

Suter U, Snipes GJ (1995) Peripheral myelin protein 22: facts and hypotheses. J Neurosci Res 40:145-151.

Tillman TS, Cascio M (2003) Effects of membrane lipids on ion channel structure and function. Cell Biochem Biophys 38:161-190.

Tobias JM, Agin DP, Pawlowski R (1962) Phospholipidcholesterol membrane model. control of resistance by ions or current flow. J Gen Physiol 45:989-1001.

van Paassen BW, van der Kooi AJ, van Spaendonck-Zwarts KY, Verhamme C, Baas F, de Visser M (2014) PMP22 related neuropathies: CharcotMarie-Tooth disease type 1A and hereditary neuropathy with liability to pressure palsies. Orphanet J Rare Dis 9:38.

Venkateswaran A, Laffitte BA, Joseph SB, Mak PA, Wilpitz DC, Edwards PA, Tontonoz P (2000) Control of cellular cholesterol efflux by the nuclear oxysterol receptor LXR alpha. Proc Natl Acad Sci U S A 97:12097-12102.

Vigo T, Nobbio L, Hummelen PV, Abbruzzese M, Mancardi G, Verpoorten N, Verhoeven K, Sereda MW, Nave KA, Timmerman V, Schenone A (2005) Experimental Charcot-Marie-Tooth type 1A: a cDNA microarrays analysis. Mol Cell Neurosci 28:703-714.

Werner HB, Krämer-Albers EM, Strenzke N, Saher G, Tenzer S, OhnoIwashita Y, De Monasterio-Schrader P, Möbius W, Moser T, Griffiths IR, Nave KA (2013) A critical role for the cholesterol-associated proteolipids PLP and M6B in myelination of the central nervous system. Glia 61:567-586.

Yamada H, Shimizu T, Tanaka T, Campbell KP, Matsumura K (1994) Dystroglycan is a binding protein of laminin and merosin in peripheral nerve. FEBS Lett 352:49-53.

Zoltewicz SJ, Lee S, Chittoor VG, Freeland SM, Rangaraju S, Zacharias DA, Notterpek L (2012) The palmitoylation state of PMP22 modulates epithelial cell morphology and migration. ASN Neuro 4:409-421.

Zyss J, Béhin A, Couvert P, Bouhour F, Sassolas A, Kolev I, Denys V, Vial C, Lacour A, Carrié A, Stojkovic T (2012) Clinical and electrophysiological characteristics of neuropathy associated with Tangier disease. J Neurol 259:1222-1226. 